\title{
LA AUDITORÍA AMBIENTAL COMO FUNCIÓN DE LA ADMINISTRACIÓN PÚBLICA EN LA PROTECCIÓN DEL BIEN PÚBLICO AMBIENTAL, PARA CONSTRUIR LA EMPRESA ECOLÓGICA COMO META DEL DESARROLLO SOSTENIBLE.
}

\author{
Alcides Francisco Antúnez Sánchez ${ }^{1}$
}

\begin{abstract}
RESUMEN
El artículo trata el control ambiental a través de la auditoría, como herramienta evaluadora de la gestión ambiental, se parte del problema científico: insuficiencias en la ordenación jurídica de la auditoría ambiental en el sector estatal, incidente en su finalidad de control ambiental en pro de la empresa ecológica y el desarrollo sostenible. Tiene como objetivo argumentar los presupuestos teóricos de la auditoría ambiental a partir de su valoración histórica, doctrinal y exegética, a fin del perfeccionamiento de su ordenación jurídica.

Los métodos utilizados fueron el teórico-jurídico, el histórico-lógico, el exegético-jurídico, el de derecho comparado, el de análisis y síntesis, como técnicas utilizamos la encuesta y la entrevista por cuestionario, las que nos permitieron formarnos criterios sobre el tema investigado para conformar el artículo. Como resultado principal se formulan los presupuestos teóricos para el futuro perfeccionamiento de la auditoría ambiental en el sector estatal y las otras formas de gestión en el contexto económico social. Su finalidad es lograr el desarrollo sostenible con la creación de empresas ecológicas, que permitan el equilibrio entre el progreso y la naturaleza.
\end{abstract}

PALABRAS CLAVES

auditoría ambiental, empresa ecológica, desarrollo sostenible.

\begin{abstract}
This article is about environmental control through auditing as an appraising tool of the environmental management, the starting point is the scientific problem: insufficiencies in in the juridical order in terms of environmental auditing in the State sector. Its final goal is environmental control on behalf of the ecocompany and the sustainable development.

Its objective is to propose theoretical arguments on environmental auditing starting from its historic, doctrinal and exegetic appraisal in order to perfect its juridical system. The methods that were implemented were the legal-theoretical, comparative law, the logic-historic, and the analytical and synthetic ones. Our techniques were surveys and interviews through questionnaires. They allowed us to assemble the present article. The main result was the proposition of theoretical arguments for perfecting the environmental auditing in the future in the state sector plus other forms of management in the social economic context. Its goal is to achieve sustainable development with the creation of eco-companies that allow balance between progress and nature.
\end{abstract}

\section{KEYWORDS}

Environmental Auditing, Eco-companies, Sustainable Development.

Depositado en agosto 15 de 2014, aprobado en octubre 31 de 2014.

1 Licenciado en Ciencias Penales del Instituto Superior del Ministerio del Interior de Cuba, Licenciado en Derecho, Universidad de Granma, República de Cuba, Especialista en Asesorías Jurídicas, Universidad de Oriente, Cuba. Formación Doctoral, Derecho Ambiental, Facultad de Derecho - Universidad de Oriente. Email: aantunez@udg.co.cu 


\section{1.- Íter histórico de la auditoría ambiental. La} preocupación por la protección del medio ambiente ha alcanzado importancia y magnitud en los últimos años al convertirse en temática de interés para el empresariado, abarca tres dimensiones: la económica, la social y la ambiental. (MEJIA HENRY, A. 2010)² El desarrollo industrial, bien equilibrado esencial para la generación de recursos que permitan crear empleos y promover la educación ambiental como bases del bienestar social y la calidad de vida, condiciones para alcanzar el desarrollo sostenible. (BERNAL PEDRAZA, A. 2009) ${ }^{3}$ Como fenómeno progresivo ha contribuido al desarrollo en diferentes países, a través de una construcción legislativa que se inicia desde el Derecho Administrativo hacia el Derecho Ambiental, dando lugar a lo que hoy se reconoce como Derecho Administrativo Ambiental; dentro de toda esta doctrina se aprecia la regulación de la institución jurídica de la auditoría ambiental como una de las herramientas de gestión ambiental.(Blanca, LOZANO CUTANDA, B. 2003) ${ }^{4} \mathrm{Se}$ valora desde el sector industrial las actividades generadoras de daños ambientales incompatibles con el desarrollo sostenible, para desarrollar políticas ambientales al implementarse los sistemas de gestión ambiental y el uso de tecnologías limpias para reducir la contaminación. (FERNÁNDEZ DE GATTA, D. 2004) $)^{5}$.

El hombre, al emplear estas tecnologías ha logrado industrializarse, al hacerlo le ha sido po- sible que la población en la Tierra llegue a los millones que la habitan. Esta industrialización ha traído contaminación ambiental y problemas ambientales, sin embargo sí se decidiera desindustrializarse para mejorar el medio ambiente deberían eliminarse miles de millones de personas, algo no lógico ni razonable el hablar de industrialización versus calidad de vida. Estos análisis, deberán evaluar el efecto de la contaminación en el hombre y en los sistemas ecológicos e implementarse los sistemas de control ambiental; también deberá distinguirse la contaminación natural y la contaminación industrial desde el comienzo de la humanidad; acelerada a partir de la Revolución Industrial, como generadora de los graves problemas ecológicos (crisis ecológica) y la no adecuada prudencia ecológica que existe en la mayoría de las regiones del planeta. (MENDEZ GUTIERREZ DEL VALLE, R. 2009) ${ }^{6}$.

Estudios y análisis desde la doctrina contable y la doctrina ius ambientalista realizados en los países del área Iberoamericana, reconocen a la auditoría ambiental como la herramienta de gestión capaz de evaluar y sentar las bases a las políticas medio ambientales en las empresas de manera adecuada, permiten ejecutar análisis de los riesgos ambientales generados en el desempeño de una actividad y evaluar su impacto con el complemento de otras herramientas como la evaluación de impacto ambiental, (ARISTA-

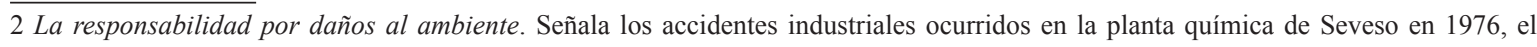
accidente nuclear de Chernóbil en 1986, el accidente petrolero Exxon Valdez en Alaska en 1989, el accidente del Parque Natural "Doña Ana" de 1998, el desastre mundial con el naufragio del Buque Prestige con vertidos de petróleo en España en el 2003. La contaminación en la Amazonía Ecuatoriana por la Trasnacional Chevron Texaco en 2013, como malos ejemplos de la protección ambiental por las industrias al no realizarse un adecuado control ambiental interno y no aplicar la Auditoría Ambiental. El Salvador. pp.1-35

3 Responsabilidad ambiental de las empresas, un compromiso ético con el desarrollo sostenible. Colombia.p.23

4 Manual de Derecho Administrativo Ambiental. 3era ed. Editora Dykinson. España. pp.2934. Coincide en los antecedentes del Ius Ambientus, reconocido en el Ius Comune: normas interdíctales como el interdicto de CloacisDigesto 43.23.3, permitían al demandante limpiar y hacer reparaciones por daños en el patrimonio producidos en ocasión de daños al entorno..., ....así mismo se previa la represión criminal por daños ocasionados al entorno y se castigaba el que ofendiere las buenas costumbres, el que echara estiércol a alguien o le manchara con lodo, o ensuciara las aguas y contaminara las cañerías y depósitos u otra cosa en perjuicio público. Digesto 47.1.1)... Con posterioridad en la Edad Medieval, por medio de la Partida III, Título XXVIII, la Ley III, determinó como res nullíus, cosa sin dueño a los animales salvajes. En la edad moderna, se han dictado normas protectoras de los recursos naturales, en especial del recurso maderero. La preocupación ante la magnitud de los problemas relacionados con la salubridad ambiental, los agentes contaminadores industriales, dieron lugar a que se crearan normativas en materia de control ambiental, dictan límites a actividades insalubres de su tutela en Salud Pública.

5 Principios del Derecho Ambiental, la responsabilidad social corporativa en materia ambiental. La Auditoría Ambiental. En Boletín Económico ICE. No. 2824. España.pp.27-43.

6 Son reconocidas a nivel mundial tres Revoluciones Industriales, la primera en la industria metalúrgica y textil, la segunda con el motor de explosión, los explosivos químicos, el desarrollo de la industria del automóvil, la industria siderúrgica y la producción de aparatos eléctricos; la tercera con la biotecnología, la microelectrónica y la informática, desde el 1800 hasta el 2007. Ministerio de Fomento. España.
} 
ZABAL OSSA, H. 2006) ${ }^{7}$ se ejecuta de forma voluntaria u obligatoria en el ordenamiento jurídico que la regule; (GOMES CANOTILHO, J.1998) ${ }^{8}$ su ejecución fusiona el objetivo prioritario de la empresa, la obtención de beneficios económicos unidos al de la protección ambiental para contribuir al desarrollo económico compatible con la conservación ambiental, al permitir el equilibrio de ambos.(PNUMA-ONU.2012).

La obra de Lucas Paccioli publicada en 494, sobre el método conocido de la "partida doble", evidencia que desde el año 254 a.n.e. se inspeccionaban y comprobaban las cuentas, factor que permitió la evolución paralela de la actividad de la Auditoría como resultado de la práctica de la Contabilidad como ciencia y herramienta de trabajo por los especialistas dedicados a la contabilidad con el desarrollo industrial. (TUA PEREDA,J. 2008 $)^{10}$ Otros documentos confirman que en los finales del siglo XIII y principios del XIV se auditaban las operaciones de los funcionarios públicos que tenían a su cargo los fondos del Estado. Para 1799 ya existían firmas acreditadas de Contadores Públicos en países como Escocia, Estados Unidos de América e Inglaterra, fueron los primeros en los cuales tomó relevancia la actividad de la Contaduría Pública ligada a la práctica de la Auditoría Estatal.(GOMEZ GARCIA, L. 2011) ${ }^{11}$.

En el siglo XX, fueron incluidas normativas jurídicas por voluntad de la Administración Pública, factor que permitió se fortaleciera el trinomio Contabilidad, Auditoría y Derecho, al cobrar nuevas dimensiones como normativa administrativa para proteger los activos contra las posibles transgresiones, tipificado con la protección del bien jurídico ambiental y otras infracciones, ubicados bajo el término genérico de los delitos ambientales con reflejo en la contabilidad directa o indirecta. Esta institución jurídica vinculada con la protección del bien jurídico ambiental, reconocida como la herramienta de gestión regulada en normas jurídicas vinculadas al Derecho Ambiental, regulada en normativas jurídicas especiales para su uniformidad, tiene un nexo causal: la exigencia de la responsabilidad ambiental y la cuantificación de los daños ambientales generados, la implementación de la responsabilidad social empresarial vinculada a la economía y a la contabilidad ambiental. Ha permitido que haya evolucionado con el transcurso del tiempo en relación con el país que la aplique y su desarrollo tecnológico industrial que posea. $\mathrm{Su}$ conexión, se aprecia al estar relacionada a los orígenes del ius ambientalismo, como parte de la Agenda Pública Internacional; los textos consultados de las Entidades Fiscalizadoras Superiores, señalan al año 1969 como su inicio.( PNUMA-ONU. 1995) ${ }^{12}$

Los textos en materia jurídica examinados revelaron que este tipo de auditoría se originó en los Estados Unidos de América a finales de los años 70 del siglo XX, apareció para evaluar la salud de la empresa con la finalidad de servir como herramienta de dirección para la gestión ambiental, ante el aumento y la complejidad de la normativa jurídica Estadual y Federal.(LEE,H. $1998)^{13}$ En la década de los años 80, se extendió a la Unión Europea como consecuencia de los intereses de las subsidiarias estadounidenses radicadas en este continente. En los países bajos, señalan al año 1984 y a Holanda como el primer

\footnotetext{
7 Auditorias Ambientales. Evaluación Ambiental Estratégica. Génesis de la evaluación de impacto ambiental y la Auditoría ambiental. Contraloría de Colombia. pp.29-66.

8 Política pública ambiental de la Unión Europea, el empresario y la Auditoría para reducir la contaminación. Editora Universidad Aberta. Portugal.pp.78-105

9 Plataforma para una industria ecológica a nivel mundial. Políticas y prácticas. La eficiencia en el uso de recursos naturales, la energética, energía renovable, facilidades financieras de la industria ecológica, transferencia de tecnologías, fomento de las industrias y trabajo ecológico. pp.17-45

10 Evolución y situación actual del pensamiento contable. La inserción de la contabilidad ambiental en la empresa. En Revista Legis de Contabilidad \& Auditoría No. 24. Colombia. pp.4-19

11 Auditoría Ambiental, voluntaria u obligatoria. Importancia de implementar la Auditoría Ambiental en la industria. En Revista de Orden Público, Estado y Derecho. No. 11. México.pp.27-29

12 Cumbre Mundial del medio ambiente. Acerca de la problemática ambiental mundial. Brasil.

13 Manual de Auditoría Medioambiental. Higiene y Seguridad. Política Nacional Ambiental desde 1969, cuerpo legislativo sobre la Evaluación de Impacto Ambiental en Leyes Federales y Estaduales. 2da ed. Editora Mc Graw-Hill. Estados Unidos de América. pp.7-29.
} 
LA AUDITORÍA AMBIENTAL COMO FUNCIÓN DE LA ADMINISTRACIÓN PÚBLICA EN LA PROTECCIÓN DEL BIEN PÚBLICO AMBIENTAL, PARA CONSTRUIR LA EMPRESA ECOLÓGICA COMO META DEL DESARROLLO

país en incorporarse a la práctica de este tipo de control, exigencias legales marcadas dentro de sus derechos internos (MURAD ROBLES, P. 2009) ${ }^{14}$. Como resultado del compromiso respaldado por la Comisión Brundtland en 1987, fue formulada la propuesta de "un desarrollo sustentable que satisfacer las necesidades de las generaciones presentes sin comprometer las posibilidades de las futuras generaciones para satisfacer las suyas".

Su iter histórico, se enmarca a partir de ser reconocida por las Entidades Fiscalizadoras Superiores en el año 1995 como una herramienta de gestión ambiental, aunque otros estudios contables se considere su génesis vinculada a la Contabilidad y a la Auditoría Social, relacionada a la Responsabilidad Social Empresarial. En esta propia década, se valora la adición de nuevos elementos tecnológicos vinculados al Comercio Internacional, la hacen mucho más compleja, completa y dinámica por parte de los sujetos económicos que la implementan; toda vez que las técnicas, métodos y objetivos de la Auditoría como actividad de control han ido de forma simétrica en evolución para poder atender y dar respuestas a las nuevas exigencias de los clientes a partir del siglo XX hasta la actualidad en el mercado de bienes y servicios, donde aparece la empresa ecológica como una solución viable.

De igual forma, la práctica de la auditoría, reconocida como una actividad de control y como una herramienta técnica de gestión, de amplia aplicación por parte de las entidades fiscalizadoras superiores, su evolución se materializa en correspondencia a las áreas geográficas donde se aplica, relacionada al nivel de desarrollo tecnológico de la industria. Se ha visto promovida por diferentes agentes, desde los gobiernos hasta las organizaciones internacionales relacionadas con este tipo de control ambiental de mane- ra directa o indirecta, a partir de la publicación de las normas ISO 14000 y 19011.

De igual manera, al analizarse los conceptos de los Organismos Internacionales que intervienen en las regulaciones en materia contable como la Asociación Americana de Contabilidad, la define como: "proceso sistemático para obtener y evaluar de manera objetiva las evidencias relacionadas con informes sobre actividades económicas y otros hechos relacionados. Su finalidad consiste en determinar el grado de correspondencia del contenido informativo con las evidencias que le dieron origen, para determinar si en dichos informes se han elaborado observando los principios establecidos para el caso".

La Cámara Internacional de Comercio, rectora de la actividad comercial por su vínculo con esta actividad de control, la reconoce como: "herramienta de gestión que comprende una evaluación sistemática, documentada, periódica y objetiva del funcionamiento de la organización ambiental. Prevé la implantación de gestión, así como los equipos de control necesarios con objeto de facilitar el control de gestión de las prácticas medio ambientales y declarar la observancia de la política de la Compañia de acuerdo con la normativa medio ambiental. Es el examen metódico que implica análisis y comprobaciones de las prácticas y procederes ambientales de una empresa o parte de ella. Este término de auditoría es sinónimo de revisión y verificación de diversos aspectos de una empre$s a "$ (BELMONTE MARTIN, I. 2009) ${ }^{15}$.

Bajo todas estas perspectivas, su expresión moderna, aparejada a su íter histórico y evolución, se considera que es la herramienta evaluadora del Sistema de Gestión Ambiental, mecanismo clave para obtener información sobre la efectividad de la gestión ambiental de la empresa

\footnotetext{
14 La Auditoría Ambiental voluntaria, concepto, antecedentes, fundamentación jurídica y evaluación. Se formaliza y ejecuta a través de la solicitud del empresario. Editora Porrúa. México.pp.263-303.

15 La empresa deja de ser considerada como la expresión concreta del capitalismo y aparece cada vez más como una unidad estratégica en un mercado internacional competitivo y un agente de utilización de tecnologías nuevas. La Ecoauditoría: un instrumento para la defensa del ambiente. Instrumento de gestión ambiental para proteger el medio ambiente dentro y fuera de la empresa. En Revista de la Facultad de Ciencias Sociales y Jurídicas de Elche. No. 4. España.pp.57-78
} 
y de sus directivos, al identificar los problemas asociados a su trabajo en materia de seguridad y ambiente laboral, los nuevos desafíos ambientales por venir, propone medidas de prevención y mitigación, complementadas con la revisión contable ambiental para conformar la empresa ecológica.

Esta acción de control, vinculada con las problemáticas ambientales del siglo XXI, no podrá ser analizada ni entenderse sí no se tiene en cuenta la perspectiva global, surgida como consecuencia de múltiples factores como efectos de la crisis ecológica: aumento de las temperaturas, agujero en la capa de ozono, desertificación, acumulación de residuos radiactivos, extensión de enfermedades como el cáncer, malaria, insalubridad del agua dulce, inseguridad alimentaria, contaminación urbana y agotamiento de los recursos renovables y no renovables vinculados de forma directa o indirecta con la institución jurídica analizada, en relación con los mega problemas ambientales que hoy acontecen. (ARNER GUERRE, A. 2013) ${ }^{16}$.

Las Entidades Fiscalizadoras Superiores, como sujeto internacional que regula esta actividad de control ambiental, establece pautas, la identifica como: la herramienta técnica de gestión para realizar la evaluación sistemática, documentada, periódica y objetiva de la efectividad de la organización auditada; la gerencia y los equipos ambientales para proteger el medio ambiente con un mejor control de las prácticas ambientales y la evaluación. Para cumplir las políticas ambientales de la empresa y las normativas legales, a partir de la institucionalización de la tutela ambiental (ANTUNEZ SANCHEZ, A. 2010$)^{17}$.

Néstor Caferrata, la ha considerado como la descripción de los procesos y actividades desarrolladas; la verificación del encuadre legal ambiental de los residuos sólidos y semisólidos, efluentes líquidos, emisiones gaseosas etc., generadas por la empresa. Deberá incluir: líneas de producción, caracterización y tratamiento de los residuos sólidos y semisólidos, caracterización y tratamiento de las emisiones gaseosas, caracterización y tratamiento de los efluentes líquidos, condiciones y medio ambiente de trabajo. Conclusiones respecto del encuadre legal y el cumplimiento de la normativa ambiental específica para cada caso, por parte del establecimiento. (CAFERRATA, N.2012) ${ }^{18}$.

La Norma ISO 14001 y 19011 la definen como: ..."el proceso sistemático, autónomo y documentado para obtener evidencias de la auditoría, evalúa de manera objetiva con el fin de determinar la extensión en que se cumplen los criterios de auditoría."...

Todos estos criterios doctrinales, conceptos administrativos y regulaciones jurídicas, caracterizan a este tipo de auditoría por ser: "generalizada al abarcar los SGA, de revisión ambiental, puntual, de conformidad, de siniestros, de riesgos, de adquisición, de seguridad e higiene, de cumplimiento de la legalidad y de recursos. Tiene en cuenta el escenario auditado donde se practicará, se clasifica: de entorno interior y de entorno exterior".

Autores cubanos señalan a esta tipología de auditoría como: la actividad de control ambiental reporta beneficios a los empresarios que aplican los Sistemas de Gestión Ambiental para conocer la contaminación generada en su empresa, para encontrar las fallas de sus sistemas productivos, la inobservancia de la legislación ambiental y tomar las medidas correctivas necesarias, complementada con la aplicación de la contabilidad ambiental para disminuir la huella ambiental. Su regulación en el ordenamiento jurídico interno cubano aparece en la Ley de la Contraloría y

\footnotetext{
16 Responsabilización voluntaria de la industria en la protección medio ambiental. La necesidad de implementar el SGA para mitigar la contaminación. Regulada en el Libro Blanco y Libro Verde complementado en las Normas EMAS. Unión Europea. Editora Lex S.A. España.pp.123-342

17 La Auditoría Ecológica, un instrumento en la gestión ambiental. La importancia de esta herramienta de gestión para introducir nuevas concepciones como empresa limpia no contaminadoras. En Revista de Derecho y Medio Ambiente. España.No.21. p.18

18 Pequeño Diccionario Jurídico Ambiental. Auditoría Ambiental. Editora Abeledo Perrot. Argentina. p.47.
} 
su Reglamento (AGUILERA MESA, I.1997) ${ }^{19}$ Otras denominaciones análogas que desde la doctrina toman posiciones otros autores, como son: la ecoauditoría, la revisión medio ambiental, el control medio ambiental, la evaluación medio ambiental y la vigilancia medio ambiental; poseen un mismo significado y fin, conocer los niveles de contaminación de una empresa y certificar sí posee una producción limpia en correspondencia al país que le utilice al implementar estas tecnologías. (BELMONTE MARTIN, I.2010) ${ }^{20}$

El autor la define como: la herramienta de gestión ambiental, evaluación sistemática, documentada, periódica y objetiva de la actividad industrial o de servicios desde diferentes ópticas: económica y contable, calidad, seguridad laboral, medio ambiente laboral, entre los indicadores medibles por el equipo auditor como pautas del programa de auditoría a aplicarse. $\mathrm{Su}$ objetivo: evaluar el impacto ambiental de la gestión empresarial generado sobre el medio ambiente y proponer las acciones correctivas para mitigar los efectos negativos identificados al realizarse esta actividad de control, concluye con la entrega de la certificación ambiental de industria limpia. Permitirá al empresario tener una imagen pública positiva, los beneficios agregados del eco etiquetado a los productos, aplicar los códigos de conducta ambiental para la producción mercantil y de servicios a través de las buenas prácticas ambientales como empresa social responsable conformada como ecoempresa.

Como herramienta de gestión empresaria ${ }^{21}$, en los países de la Unión Europea, Latinoamérica y el Caribe en relación a sus ordenamientos jurídicos, idioma, cultura y realidad económico- social, es capaz de evaluar y sentar las bases de una política medio ambiental dirigida a estos empresarios estatales, no estatales y otras formas de gestión reconocidas, tiene como finalidad, ejecutar análisis de los riesgos ambientales que pudieran generarse en el desempeño de su actividad y evaluar los impactos generados. Entre otras características analizadas por este autor, este tipo de auditoría es de obligada obediencia en la legislación que la tipifique al implementarse las normas ISO 14000 y 19011 o voluntaria, la más solicitada al ser mayoritario el sector privado.

El vínculo e importancia con los conceptos de Economía y la Contabilidad Ambiental establecidos por el PNUMA (LINARES LLAMAS,P.2010) ${ }^{22}$, necesarios para ejecutar esta tipología de auditoría por parte de los auditores de las Contralorías y las Sociedades Mercantiles, con normativas especiales en los ordenamientos jurídicos en relación a la regulación de su tutela a través de Leyes Orgánica de Medio Ambiente, Leyes de Contralorías y Leyes de Auditoría Ambiental entre otras, relacionada en su práctica a otras herramientas de gestión, con la gestión social empresarial y la responsabilidad ambiental.

Su ejecución por los auditores de las Sociedades Mercantiles que practican la auditoría al sector privado, habilitados por la EFS o el órgano acreditado en mandato del Estado para ejercitar esta función pública a través de la concesión administrativa. Podrá ser también realizada a la empresa estatal por la EFS de manera obligatoria $u$ aleatoria, es reconocida y regulada en los ordenamientos jurídicos como: una prestación de servicio público, una actividad de control y fomento; para su ejecución media la suscrip-

\footnotetext{
19 Algunos autores dejan entrever que esta actividad de control se vincula a la construcción de la empresa ecológica, con concepciones desde las ciencias contables, dan paso a la doctrina ius ambientalista, ligada a las herramientas de gestión como nexo en este tránsito. Proyecto de Programas para la realización de auditorías de gestión ambiental. pp.45-51

20 Coinciden en el uso del concepto de Ecoauditoría como instrumento de gestión ambiental. La Ecoauditoría: instrumento para la defensa del medio ambiente. En Revista Electrónica de la Facultad de Ciencias Jurídicas y Sociales de Elche. p.13

21 Instrumento de gestión ambiental, utilizado en las empresas para el conocimiento de su situación y de los efectos que tiene la actividad que desarrolla sobre el medio ambiente; sí cumple con las normas regulatorias y leyes, evalúa la efectividad del SGA; evita sanciones penales y aumenta la rentabilidad económico-financiera.

22 Economía y Medio Ambiente: herramientas de valoración industrial. Se valora por los ecologistas puros que el medio ambiente no humano, ecosistemas y bienes naturales no deberán ser valorados, toda vez que se le incorporarían juicios de valor humano, no los propios del medio ambiente. Editora Mc Graw-Hill. España. pp.1-29
} 
ción de un contrato de servicios, concluye con la entrega del informe de los resultados de la auditoría y la certificación ambiental.

\section{1 ¿ACTIVIDAD DE CONTROL, DE SERVICIO PÚBLICO, DE FOMENTO Y DE GESTIÓN ECONÓMICA?}

La concepción de servicio público, concepto controvertido, entendido de diversas formas y mutando en dependencia de las circunstancias políticas, económicas y sociales de los Estados; en la doctrina francesa autores entre los que se destaca León Duguit, con sus diferencias la consideran como la piedra angular del Derecho Administrativo clásico, elementos imprescindibles a la hora de determinarlo. A partir de la manifestación de esta actividad, se identifican sus elementos: necesidad de la sociedad o generalidad, titularidad estatal, el régimen jurídico permite que la Administración Pública gestione de manera directa o indirecta el servicio como el control, la continuidad, uniformidad e igualdad de trato para todos los ciudadanos. Como categoría se ha concebido como forma de actividad estatal y actividad técnica, como categoría rectora al interés público; realizada y asegurada de manera continua, regular y uniforme, tutelada por la Administración Pública y gestionada de forma directa por ésta o indirecta por sujetos autónomos autorizados para ello, bajo un régimen jurídico especial, destinada a la satisfacción de un interés general. Se contempla la forma de gestión la mixta, gestión esta que se lleva a cabo a través de sociedades mercantiles con una concesión, la Administración participa por sí o por medio de una entidad pública en concurrencia con personas naturales o jurídicas. Como actividad de control (Administración Policía), sus destinatarios son: los órganos, organismos, organizaciones y entidades sujetos a las acciones de control que por Ley se establecen, obligados a mantener sistemas de control interno conforme a sus características, competencias y atribuciones institucionales. Su finali- dad: mantener, controlar y evaluar la efectividad del sistema en las instancias de dirección que le competan. Su importancia va dirigida a comprobar la aplicación de las políticas del Estado en la preservación de las finanzas públicas y el control económico administrativo (GORDILLO, A.2006) $)^{23}$.

En materia de protección ambiental este tipo de control ha mutado, se valora la aplicación de otros mecanismos de control que se le han incorporado en el transcurso de estos años, conocidos como técnicas de tutela ambiental, realizadas a través de la aplicación del control interno, la fiscalización, la inspección, la auditoría, el ordenamiento ambiental, la información y educación ambiental. Pueden ser preventivos, para esto se establece la aplicación de instrumentos de control como: autorizaciones, aprobaciones, permisos, licencias, concesiones y otros. Los de control ambiental, se establecen a través de la Auditoría Ambiental, la policía ambiental, la supervisión ambiental y otros. Son aplicados para mejorar la conciencia ambiental e identificar los riesgos dentro de estas empresas para el desarrollo sostenible (PÉREZ MORENO, A.1993). ${ }^{24}$

Como actividad de gestión económica, con el uso de instrumentos económicos, considerados por la doctrina como una alternativa para atenuar los efectos de la problemática ambiental, modifican conductas de producción y consumo por otras sostenibles. Aparecen en este escenario la alternativa jurídico-económica, es el caso del tributo ambiental, mecanismo utilizado para obtener un desarrollo limpio -Protocolo de Kioto-, permite lograr que quien contamine pague para una mejor responsabilidad empresarial. Se valora su vinculación con esta actividad de control ambiental a las empresas, en relación a la actividad que realice, implementado y controlada a través del Fisco en normativas tributarias, en el caso a través del ecoimpuesto vinculado al vertido ambiental y a la auditoría (PIGOU, A. 1993). ${ }^{25}$

23 Tratado de Derecho Administrativo. Aborda la promoción del bienestar social. 8va ed. Editora Macchi. Argentina. p.12. 24 Instrumentos de tutela ambiental. El régimen tributario en materia ambiental. Editora Trivium S.A. España. pp.8-57.

25 Pionero de los tributos con finalidad ambiental, propuso hace más de cuatro décadas un gravamen por emisión de contaminantes, con la finalidad de alcanzar el nivel óptimo de contaminación mediante la nivelación del tributo al costo marginal externo para cada nivel de producción. 
En el caso del fomento ambiental, es el estímulo para que las empresas sean menos contaminadoras, se regula en normativas jurídicas a través de Leyes de Fomento. Estos estímulos fiscales por la doctrina ambiental son conocidos como "impuestos verdes o reformas fiscales verdes", utilizadas como herramientas de mercado, aplicadas al uso del transporte híbrido o eléctrico en respuesta a la contaminación vehicular, en el reciclaje de botellas plásticas por la industria, al control de la deforestación boscosa, al tratamiento al agua potable y desechos sólidos utilizados en la industria, para conservar la biodiversidad y el uso de combustibles fósiles -modificar la matriz energética- (RÍOS GUAL, J.2007) ${ }^{26}$. Como ecología mercantilista, se reconocen dos variables por la doctrina ambientalista, una a través de la competitividad empresarial y la protección ambiental con la entrega de instrumentos de acreditación ambiental (DOPAZO FRAGUIO, P. 2001). ${ }^{27}$

Todos estos conceptos, principios y elementos establecidos desde la doctrina administrativa relacionada con otras ramas del Derecho, este tipo de actividad de control deberá estar sustentada; los ordenamientos jurídicos revisados se reconoce como actividad de control y de servicio público. Sí entendemos que todo servicio público conlleva en sí acciones de control para medir su eficacia y eficiencia de las actividades auditables ambientales en estas empresas, como elementos de actividad pública visibles en la empresa estatal. Dentro de esta materia medio ambiental, pudiera ser conformado a través del ordenamiento ambiental como parte del desarrollo urbanístico, la licencia ambiental, la Evaluación de Impacto Ambiental, el Sistema de Inspección Ambiental y la recogida de desechos sólidos, todos tributan a la ejecución de la Auditoría Ambiental por su vínculo administrativo. La Administración Pública al practicarla para preservar el bien jurídico ambiental, la realiza de forma obligatoria a través de un plan, se va- lora su vínculo con la inspección y a la potestad sancionadora que posee esta Administración Pública de sus funcionarios ante sus faltas por cometer daños a los recursos naturales del Estado. Culmina todo este proceso con la entrega del resultado del informe final de la auditoría, sí cumple con las regulaciones y exigencias para ser reconocida como una empresa ecológica, le certifican con la ecoetiqueta.

Como tipología de auditoría, se distingue de la actividad inspectora, como potestad inspectora de la Administración Pública, toda vez que la inspección ambiental, tiene como objeto proteger la legalidad, la vigilancia y fiscalización para revisar el nivel de observancia por parte de los sujetos obligados. Se ejecuta a través de un plan anual, con procedimientos específicos, dirigida a los ecosistemas de interés de esta $\mathrm{Au}-$ toridad Ambiental, inspecciona el resultado de las medidas dejadas en la Licencia Ambiental otorgada como respuesta de la evaluación de impacto ambiental practicada o por denuncias públicas recibidas, su alcance es limitado. La función inspectora es la actividad ejercida de forma directa por la propia Administración in situ, con carácter aleatorio, discrecional y esencial; ligada al ejercicio de la potestad sancionadora, es una función de control configurada a una entidad por la complejidad de los riesgos ambientales que deberán afrontarse por la sociedad actual. Es reconocida como policía administrativa con alcance horizontal (REBOLLO PUIG, M.2011) ${ }^{28}$ Ejercida de forma directa, esta función de control se configura a una entidad por la complejidad de los riesgos ambientales que deberá afrontar, con un alcance horizontal.

La auditoría, como actividad de control a los bienes públicos ambientales, permite a los empresarios la concreción de la empresa ecológica y la contrapartida a la inspección ambiental. Revisa la implementación dentro de la organi-

\footnotetext{
26 La reingeniería aplicada al mundo empresarial del siglo XXI. Sostiene que tres son las fuerzas que por separado y en combinación, impulsan a las compañías a penetrar en un territorio, desconocidos por ejecutivos y administradores: los clientes, la competencia y el cambio. Vinculadas a las herramientas de gestión ambiental para conformar la empresa ecológica. En Revista de Empresas. España. pp.1-10. 27 Régimen Jurídico de las marcas de calidad ambiental: etiqueta ecológica y tutela ambiental. Editora Exlibris.1era Ed.España.p.21 28 La posición de autores desde las ciencias jurídicas, consideran la potestad inspectora como una acción directa de la Administración Pública dirigida a los servicios públicos de esta Administración, consultar obras de. La Actividad Inspectora. Editora Iustel.España.pp.1-57.
} 
zación el sistema contable ambiental a través de procesos y procedimientos por el equipo auditor que la practique y la observancia de la legalidad en relación a las normas contables y de auditoría establecidas en la normativa general. Es ejecutada conforme al plan anual de actividades de control que se conforme por parte de la Contraloría, comprenderá lugares ambientales o áreas críticas con problemas de contaminación generados por las diferentes actividades desarrolladas en áreas rurales, cuencas, bahías, áreas naturales protegidas, etc., para identificar los diversos sectores que tengan competencias ambientales. Las actividades incluyen las que realiza la empresa auditada, asociadas con el manejo o contención de sustancias peligrosas, incluyen materiales y residuos con propiedades corrosivas, explosivas, tóxicas, inflamables o de algún modo contaminantes y los procesos o instalaciones que generen otras formas de contaminación ambiental, de aquí que exista otra clasificación menos utilizada, la aleatoria, en relación con el interés por este sujeto estatal ante un problemática ambiental de interés nacional. En su ejecución revisará la observancia de la legislación y la normatividad ambiental por el auditado. Se revisarán y verificarán aspectos como: agua, aire, residuos peligrosos y no peligrosos, suelo y subsuelo. Las fuentes de abasto de agua, descargas de agua residual, procesos y servicios industriales, sitios de almacenaje de materias primas, almacenaje temporal de residuos peligrosos y fuentes de emisión a la atmósfera. La recopilación de información relativa a la región donde esta ubicada la industria, incluidos: mapa de localización de instalaciones, industria y colindancias, planos de edificios e instalaciones, tipo de construcción, drenaje de la empresa, de aquí que se reconozca la participación ciudadana en la práctica de esta evaluación ambiental, al distinguirla de la actividad inspectora (BERNAL FISIL, F.2010) ${ }^{29}$

Su regulación aparece como institución jurídica a partir de ser reconocida en la firma de Tratados y Convenios Internacionales con las Entidades Fiscalizadoras Superiores y Organismos Internacionales, Constituciones, Código Ambiental, Ley Orgánica Ambiental, Ley de Auditoría Ambiental y Ley de Contraloría; vinculada en su aplicación por normativas jurídicas con rango de Ley en materias de Administración Pública Ambiental, Orgánicas de la Administración, Gestión Ambiental, Responsabilidad Ambiental, Control de la Contaminación Ambiental, de Salud, Agua, Vida Silvestre, Parques Nacionales, Corredores Marinos, Agraria y Ordenanzas Municipales, entre otras. Complementadas con las normas ISO, las EMAS y las disposiciones de las Entidades Fiscalizadoras, consideran estos autores. Al exigir la responsabilidad ambiental a los auditados, se establecen en norma jurídica su tramitación con procesos penales ante Fiscalías Ambientales, la solución final de estos conflictos se realizará en sedes judiciales en: los Tribunales Ambientales, reguladas con rango de Ley (BURDYSHAW, C.2013). ${ }^{30}$

Es en todo este escenario socio-económico, la auditoría ambiental responde a las necesidades sociales como herramienta de protección del medio ambiente, es susceptible de integrarse en la realización de las revisiones clásicas que se establecen en otras ramas de la economía industrial, le ha permitido evolucionar a otras tipologías de auditorías reconocidas en normativas legales como las: de legalidad, financiera, de cumplimiento y de gestión; estas revisan en sus programas de auditorías aspectos vinculados con la protección ambiental, brindan a estos empresarios una mejor información en esta materia y responden a las necesidades sociales cuya meta es la sostenibilidad ambiental. Es realizada en base a los criterios como: nivel de importancia y de urgencia de los problemas ambientales detectados, el alcance y complejidad de las actividades que realiza la empresa, como influyen en el ambiente, el volumen de las emisiones de contaminación y el historial de los problemas medio ambientales. Como he-

29 Auditoría Ambiental o Ecoauditoría. En Revista Actualidad Empresarial. No. 201. España. pp.1-2.

30 ¿Qué puede aprender Chile de la experiencia de otros Tribunales Ambientales en el mundo? En el mundo los tribunales ambientales, reconocidos en 41 países y por sus resultados en la promoción de un desarrollo ecológico sostenible, su composición se integra por juristas especializados en Derecho Administrativo o Ambiental, profesionales de las ciencias económicas especializados en materia ambiental, con diez años de experticia. En Revista FIMA. Chile. pp.93-120 
LA AUDITORÍA AMBIENTAL COMO FUNCIÓN DE LA ADMINISTRACIÓN PÚBLICA EN LA PROTECCIÓN DEL BIEN PÚBLICO AMBIENTAL, PARA CONSTRUIR LA EMPRESA ECOLÓGICA COMO META DEL DESARROLLO

rramienta vinculada con los principios del Derecho Ambiental como: una acción preventiva, de cautela, de cooperación, de quien contamina paga, de evaluación de impacto ambiental, de responsabilidad, de participación ciudadana, de equidad intergeneracional, de progresividad y de sustentabilidad (CAFERRATA, N. 2010) ${ }^{31}$

\subsection{ANÁLISIS LEGISLATIVO DE LA ACTIVIDAD DE CONTROL AMBIEN- TAL A TRAVÉS DE LA AUDITORÍA.}

La denominación de auditoría ambiental como término a manejarse en el artículo, al ser la terminología de mayor uso en la doctrina ius administrativa y la ius ambientalista consultada, la reconocida en los ordenamientos jurídicos analizados, la utilizada por los organismos y organizaciones internacionales vinculados al control, la manejada por la contabilidad y el comercio.

La opinión de autores de la Unión Europea, desde los saberes contables, coinciden en confirmar que la práctica de esta auditoría se aprecia vinculada a los conceptos de economía y contabilidad ambiental, permiten a la empresa reducir los costes al implementar las producciones limpias y obtener la certificación ambiental como valor agregado de la actividad comercial, protege la salud laboral al minimizar los riesgos y controlar los niveles contaminación al cumplir con las regulaciones establecidas por el ius comune; estas normativas jurídicas parten desde la firma de Tratados Internacionales, Constitución, Códigos Ambientales, Leyes Ambientales y Leyes de Auditoría Ambiental; complementadas para su ejecución por las normas voluntarias conocidas como las EMAS y las ISO 14000 y 19 011. Su tutela la posee la Entidad Fiscalizadora, se vincula a otras herramien- tas de gestión y a la responsabilidad social empresarial. Ha ido en evolución con la aplicación de otros instrumentos que se le han incorporado desde el pasado siglo, como regulaciones y herramientas entre las que se destacan: la cobertura a través del seguro ambiental, la aplicación de incentivos fiscales, la tributación ambiental como tipo impositivo en materia de tributos, las tecnologías limpias y la responsabilidad objetiva (PÁEZ SANDUBETE, J.M.2008) ${ }^{32}$.

Los criterios de juristas dedicados al estudio de esta rama del derecho consultados (LOZANO CUTANDA, B.2009) $)^{33}$ coinciden que este Derecho Ambiental como derecho de nueva creación en materia doctrinal y normativa, es dinámico y variable, vinculada con otras ramas del Derecho y con otros saberes por su transversalidad, pero adolece de un adecuado respeto en torno a su obediencia por parte de los sujetos obligados a cumplirlas (OJEDA MESTRE,R.2012) (34 $^{34}$ Otros textos consultados, señalan que por ser un derecho humano reconocido desde la doctrina internacional, no se comprende por qué la Declaración Universal de los Derechos $\mathrm{Hu}-$ manos no existió ninguna referencia al medio ambiente, apenas se reguló en la legislación de aquel período o en alguna Constitución de la época. Estos derechos de tercera generación, denominados nuevos derechos surgieron como respuesta al problema de la contaminación de las libertades por los nuevos avances tecnológicos: calidad de vida, medio ambiente, libertad informática y el consumo, suelen incluirse los que protegen bienes como el patrimonio histórico y cultural de la humanidad, el derecho a la autodeterminación y la defensa del patrimonio genético de la especie humana (DE MEDEIROS GARCIA, L. 2010). ${ }^{35}$

\footnotetext{
31 Principios del Derecho Ambiental. Editora Abeledo Perrot. Argentina. pp.7-69

32 Toman posición desde la ciencias contables sobre la Auditoría Ambiental, sus beneficios, limitantes y consecuencias negativas para mitigar los problemas ambientales. La Auditoría Medio Ambiental en la Unión Europea, una perspectiva contable. En Revista Contable. España.p.9.

33 En las ciencias jurídicas, algunos autores consideran la importancia de la Auditoría Ambiental, su nexo con el Derecho Ambiental. Actualidad del Derecho Ambiental Comunitario. En Revista de Derecho Administrativo Económico. No. 20.Brasil. pp.1-20.

34 El nuevo Derecho Ambiental. Le considera caro, complejo, moderno, cientificista, multidisciplinario, de expertos, preventivo y correctivo, indexado al desarrollo económico, es procesalista, trasversal, entre otras. En Revista de la Universidad de Cuauhtémoc No.8. México.

35 Derecho Ambiental Constitucional. El derecho interno ambiental a partir de la protección constitucional. 2da ed. Editora Jus Podivm. Brasil.pp.133-204.
} 
Investigaciones jurídicas realizadas en el país y por otros autores foráneos (JUSTE RUIZ, J. 2009) $)^{36}$, consideran que el Derecho Ambiental Internacional ha estado vinculado con el desarrollo del Derecho Internacional Público en las etapas histórico-jurídicas de evolución de la ciencia del Derecho, para dar respuestas a la problemática ambiental, apreciado como ley blanda en cuanto a su obediencia por parte de sus sujetos. Otros autores, desde las ciencias jurídicas en Latinoamérica y el Caribe (SALES DE FREITAS, J.2013) ${ }^{37}$, consideran a esta rama del Derecho pese a las insuficiencias descritas, ha entrado a resolver la cuestión de la polución, la responsabilidad ambiental a partir de la normativa constitucional, en Leyes especiales como: las de crimen ambiental, forestal, de la auditoría ambiental; relacionadas con el daño ambiental y su cuantificación, los incentivos fiscales con la tributación ambiental y la cobertura a través del seguro ambiental. Reconocen el vínculo que posee con otras ramas de las ciencias jurídicas y con otras ciencias como: la ecología, la contabilidad, la sociología, la historia y la economía ambiental entre otras, permiten a estos empresarios tomar decisiones para mitigar la contaminación generada por la producción industrial versus sostenibilidad en el desarrollo de la industria ecológica, a partir de todo este íter histórico que la reconoce como herramienta de gestión ambiental promovida por la Administración Pública a través del fomento como el instrumento de prevención para mitigar la contaminación.

El Derecho Ambiental, vinculado a los mecanismos de comando y control descritos en el Programa de las Naciones Unidas para la Protección del Medio Ambiente, señalan la importancia de poder contar en el escenario internacional con una institución similar a la Organización Mundial del
Comercio, que sirva como foro de negociación de las políticas relacionadas con la protección medio ambiental y revertir la situación que impera, para tributar al equilibrio entre el progreso y la protección de los recursos naturales, aún no logrado por los líderes mundiales (ANTÚNEZ SÁNCHEZ, A.2005). ${ }^{38}$

Los conceptos y las características presentes en esta tipología de Auditoría, reconocida como la herramienta de gestión ambiental, vinculada con otras herramientas e instrumentos al realizarse por los auditores, reconocida en la norma legal como una actividad de control y a la vez como servicio público en la Doctrina Jurídica de Iberoamérica; tutelada por la Administración Pública con un fin concreto, preservar este bien jurídico ambiental para el desarrollo sostenible, a su vez es reconocida su interdisciplinariedad, transdisciplinariedad y multidisciplinariedad, al intervenir en su ejecución profesionales de las ciencias en relación con el escenario a auditarse, de aquí que sea multidimensional (MARTIN MATEO, R. 1982). ${ }^{39}$

Este tipo de control ambiental, posee ventajas en su aplicación, a partir de: la implementación del SGA, el uso de tecnologías limpias, la aplicación de la contabilidad ambiental, la obediencia a la legislación, permite obtener la cobertura financiera a través de la póliza ambiental, y con ello lograr una empresa ecológica sostenible; sus limitantes consideramos están identificas con la obsolescencia tecnológica, los elevados costes de las tecnologías limpias, los costes del contrato de servicio, la heterogeneidad industrial y las formas de organización. Como consecuencias negativas están circunscritas a: ser empresas contaminadoras al medio ambiente, los costes del contrato de auditoría, les impedirán obtener la certificación ambiental

\footnotetext{
36 En tal sentido, otras posiciones desde las ciencias jurídicas refieren el vínculo del Derecho Ambiental Internacional con el Derecho Internacional Público y en particular la Auditoría Ambiental, con la firma de Tratados y Convenios. La evolución del Derecho Internacional del Medio Ambiente. España. 2009. pp.467-474.

37 Posiciones asumidas por autores desde las ciencias jurídicas, reconocen los aportes de esta rama del Derecho a la protección medioambiental. Auditoría Externa Ambiental como instrumento en la defensa del medio ambiente. En Revista de Jure No.20. Brasil. pp.293-309

38 La jurisdicción de la Auditoría Ambiental. Realizada por las Contralorías, Unidades de Auditoría y Sociedades Mercantiles. En Revista EumeNed. España.

39 Nuevo Derecho Energético. Refuerza la protección del bien jurídico ambiental en la Unión Europea. Editora Ieal. España. 1982. p.65.
} 
LA AUDITORÍA AMBIENTAL COMO FUNCIÓN DE LA ADMINISTRACIÓN PÚBLICA EN LA PROTECCIÓN DEL BIEN PÚBLICO AMBIENTAL, PARA CONSTRUIR LA EMPRESA ECOLÓGICA COMO META DEL DESARROLLO

SOSTENIBLE.

v/s desarrollo sostenible a estos empresarios no concientizados con la problemática ambiental y como resolverla.

La justificación de realizar esta actividad de control, recaerá en: la importancia de practicarla por estos empresarios a sus empresas a partir de ejecutar el control interno sistemático, en atención a estos temas ambientales, a los acuerdos internacionales en materia ambiental firmados por los países, las normativas jurídicas internas, las pautas trazadas por los bloques comerciales (UNASUR, MERCOSUR, ALBA, GATT, UNION EUROPEA), la Agenda 21, el Protocolo de Montreal (Capa de Ozono), la Convención sobre Diversidad Biológica, el impacto en las decisiones y su repercusión económica al no implementarse la contabilidad ambiental. Para lograr esto, estos empresarios tendrán que aplicar estrategias para reducir los niveles de contaminación, ahorrar energía, utilizar tecnologías limpias, ahorrar materias primas, aplicar las técnicas de reciclaje, aplicar la reingeniería empresarial, realizar alianzas estratégicas; es aquí, donde la auditoría ambiental juega un rol privilegiado para conformar la empresa ecológica y con ello lograr el desarrollo sostenible.

Emilio Valdivia Aguilar, experto en la práctica de auditorías realizada por agencias internacionales, señalaba: dentro de la ejecución de esta actividad de control ambiental, deberán quedar definidos los conceptos de economía ambiental, la persecución social del ambiente, los principios universales del Derecho Ambiental y desde el punto de vista de la generación de la contaminación, definirse cuál es la responsabilidad de la Naturaleza y cual por las actividades del Hombre, estos análisis permitirán actuar conforme a derecho para pagar por el daño en la evaluación realizada por los auditores. Proseguía en esta entrevista con las interrogantes a realizar dentro de la empresa a los empresarios: ¿Se deberá acatar la legislación de protección del ambiente por convicción o por obligación?, ¿Por qué lo hacen los empresarios? ¿Todos lo hacen? ¿Por qué tiene que intervenir el Derecho Ambiental? En materia de seguridad y salud laboral las empresas radicadas en el país cumplen de manera adecuada la legislación, contrario a lo que ocurre cuando estas son vendidas a empresarios extranjeros (VALDIVIA AGUILAR, E. 2014). ${ }^{40}$ Jaime Wolisky, experto en la ejecución de las auditorías ambientales, expresaba que: la temática contable dentro de esta acción de control es de gran relevancia, le permite al empresario conocer los costes asignados a la protección ambiental en su empresa, para evaluarlos a través del control interno y cuando sea solicitada una evaluación interna a través de la actividad de control ambiental (WOLISKY, J. 2009). ${ }^{41}$

\section{ELEMENTOS DE LA AUDITORÍA AMBIENTAL}

Esta tipología de auditoría es practicada en dependencia de las condiciones que la enmarquen, de los objetivos específicos que la motivan y del nivel de desarrollo que la organización empresarial tenga, comparte un objetivo común entregar información documentada y validada sobre diferentes aspectos de la situación ambiental de la entidad auditada al identificar los riesgos e impactos asociados, el examen y la evaluación de las prácticas existentes para mejorar el desempeño ambiental, permitirá comprobar el respeto de la legislación y los estándares ambientales de relevancia (PADIN, M. 2011) ${ }^{42}$

Con esta evaluación de la gestión ambiental realizada a la empresa, como uno de los principios básicos que la Comunidad Internacional ha reconocido para lograr una gestión ambiental eficaz y eficiente, es contar con mecanismos y herramientas que permitan a las sociedades proteger el derecho de las personas a disfrutar de un ambiente adecuado para su desarrollo, salud y bienestar, con mecanismos que permitan a cualquier persona tener acceso a la justicia ambiental, ante el fenómeno de la globalización

40 Perito en Gestión Ambiental Internacional. Procuraduría Federal del Medio Ambiente. México. Entrevista realizada en fecha 18 de julio 2014. Hora: 22.00 p.m. Fecha: 21 de julio 2014. Hora: 8.45 p.m. Email: ecomunic@yahoo.com.mx

41 Auditor Ambiental y Contador Contable Internacional. Argentina. Email: wolinsky@wolinsky.com.ar. hptt//www.wolinsky.com.ar 42 La Auditoría Ambiental y las Normas ISO 14000. En Revista Foro de Contabilidad Ambiental y Social. No.5. La responsabilidad ambiental empresarial. Argentina. p.37. 
internacional la que trae fenómenos aparejados en acaparar la producción de bienes, servicios, comercios entre otros de un producto por Asociaciones Internacionales, las reformas energéticas y de recursos naturales que se realizan en Latinoamérica y el Caribe en la economía, salud, ciudadanía y ambiente, como entonces realizar reformas sostenibles adecuadas. Permitirá además, conocer al equipo auditor el grado de economía, eficiencia, y eficacia, calidad e impacto en la planificación, control y uso de los recursos naturales, la conservación y la protección del medio ambiente, como características fundamentales en este proceso de planeación y práctica de esta actividad de control ambiental (LACRUZ MORENO, F.2005). ${ }^{53}$ De aquí, que consideremos estemos en presencia de los elementos subjetivos que se reconocen en este relación administrativa: Auditor: auditores certificados que pertenecen a las Contralorías o a las Sociedades Mercantiles de Auditoría. (Habilitados en el Registro de Auditores). Auditados: Empresas Estatales, Empresas no Estatales y otras formas de gestión.

Sí estas tienen establecido un SGA, esta Auditoría permitirá evaluar por este equipo auditor sí el mismo satisface los criterios del control y comunicar los resultados de este proceso a los directivos de la organización empresarial en la condición de auditados en esta relación jurídica. Los análisis de los temas de obediencia legal y de residuos en las auditorías son los de mayor relevancia para las organizaciones auditadas, en muchas ocasiones carecen de información con respecto a la conducta ambiental en sus actividades, monitoreadas a través de las herramientas reconocidas en las Leyes Ambientales. Este diagnóstico o estudio previo, permitirá la identificación y análisis de los riesgos que enfrentará la organización para alcanzar sus objetivos y metas, las principales fuentes de pérdidas y visualizar sus posibles alternativas de solución. Son identificados como elementos formales en su práctica a través de la aplicación de las directrices de la
Auditoría Ambiental de las EFS, las Normas ISO 14000 y 19011, las EMAS, el uso de las Tecnologías Limpias para obtener producciones no contaminadoras, el uso del SGA para conocer los índices de contaminación, las Normas de Auditoría y las Normas y Principios Contables.

En aquellas organizaciones con trayectoria por los resultados obtenidos en las auditorías practicadas con anterioridad y su evaluación obtenida haya resultado positiva, esta actividad de control será orientada a la identificación de opciones para la minimización de los residuos y la reducción de riesgos de mejoras continuas. Es de entenderse entonces, que este término Auditoría Ambiental desde sus principios teóricos, es también utilizado dentro del contenido de las auditorías externas independientes, conocidas como Auditorías Legislativas o del sector público por las EFS. Es en este sector público, donde se practican tres tipologías de auditorías reconocidas como: la financiera, la de conformidad y la de rendimiento, no se diferencian de los otros tipos de auditorías realizadas por las EFS, al abordarse cuestiones relacionadas con el medio ambiente, los recursos naturales y el desarrollo sostenible (LOMBARDERO RODIL, J.2008). ${ }^{54}$ Son considerados por este autor, como elementos objetivos que no deberán de omitirse en los resultados del informe, la formalización de la auditoría a través de un contrato de servicio público, de manera voluntaria u obligatoria, en algunos casos puede ser considerada como aleatoria, en su práctica se integrarán dentro del equipo auditor diversas profesiones de las ciencias, saberes y principios -Transversalidad- en relación con el escenario a auditarse, se practicará para conocer sí la empresa cumple con los índices de contaminación requeridos en la normas ambientales ISO al implementar los SGA, el uso de tecnologías limpias y la contabilidad ambiental dentro de su sistema contable, como los de mayor relevancia; este equipo auditor para su ejecución utilizará el programa para este tipo de Auditoría,

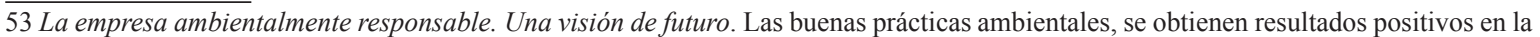
protección. En Revista de Economía No.7. Venezuela. pp.39-58.

54 Guía de auditorías ambientales para las Entidades Fiscalizadoras Superiores. PNUMA-ONU. hptt//www.efs.org Manual para la formación en medio ambiente. Capítulo: Auditorías Ambientales en el sector empresarial. Editora Lex Nova. España. pp.15-143. 
LA AUDITORÍA AMBIENTAL COMO FUNCIÓN DE LA ADMINISTRACIÓN PÚBLICA EN LA PROTECCIÓN DEL BIEN PÚBLICO AMBIENTAL, PARA CONSTRUIR LA EMPRESA ECOLÓGICA COMO META DEL DESARROLLO

concluye con la entrega de los resultados en el informe final de la auditoría realizada, el que otorgará sí son cumplidas todas las etapas de la Auditoría de manera favorable, el certificado ambiental -Ecoetiqueta-.

Sus principios se determinan por el ejercicio práctico como los de: economía, en igualdad de condiciones de calidad de bienes y servicios se obtengan al menor costo; eficiencia, la asignación de los recursos sea más útil para maximizar los resultados; eficacia, sus resultados sean logrados de manera oportuna y guarden relación con sus objetivos y metas y transparencia, referido a la difusión de los resultados de la auditoría con el fin de sensibilizar y concientizar a los directivos y trabajadores en general sobre la necesidad de conservar el ambiente y contribuir al desarrollo sostenible: sostenibilidad ambiental, gestión, programas, proyectos y actividades de la entidad deben conducir al aumento económico, a la elevación de la calidad de vida y al bienestar social, sin agotar la base de los recursos naturales renovables en que se sustenta, ni deteriorar el medio ambiente o el derecho de las generaciones futuras a utilizarlo para la satisfacción de sus propias necesidades (MARTIN MATEO, R.1991). ${ }^{55}$

Por tanto, el eje fundamental característico dentro de la organización empresarial es implementar el SGA, como el componente clave que permitirá a estos empresarios mitigar la contaminación en sus empresas. De aquí, que estime que la multidimensionalidad de la auditoría ambiental se integrará por ser un proceso sistémico, un procedimiento, una herramienta de gestión y una actividad administrativa.

\subsection{LA PROTECCIÓN DEL BIEN PÚBLICOAMBIENTALVISTADESDE LA ARISTA DEL CONSTITUCIONALISMO.}

Los elementos que consagran la institución jurídica, se aprecian al reflejarse en los ordena- mientos jurídicos que fueron analizados, a partir de las Constituciones estudiadas y su desarrollo jurídico en el derecho sustantivo en materia de protección del medio ambiente al introducirse nuevas tecnologías en este siglo y las que están por venir. Esta evolución y desarrollo del Derecho Ambiental Latinoamericano y su aplicación ha tenido en cuenta como proceso histórico para su formación el período comprendido entre la conferencia de las Naciones Unidas sobre el Medio Humano y la conferencia de las Naciones Unidas sobre el Medio Ambiente y el Desarrollo, en estos cónclaves fueron abordadas cuestiones en materia de conservación del medio ambiente, pendientes a solucionarse por los Estadistas en los próximos congresos internacionales a convocarse (PNUMA-ONU.1992). ${ }^{56}$ En todo este análisis realizado, se constata los avances del Derecho Ambiental en la región de Latinoamérica y el Caribe, reflejan el marco jurídico donde se sustenta, permite cumplir las responsabilidades y funciones a los ciudadanos y a la Administración Pública. Se han incorporado en estos ordenamientos jurídicos instituciones, categorías, consideraciones técnicas, principios, herramientas y mecanismos necesarios para prevenir o corregir los efectos adversos al ambiente y a los recursos naturales generados en procesos productivos y de consumo, para fortalecer la gestión ambiental (PNUMA-ONU.1992). ${ }^{57}$

La historia política de Latinoamérica, confirma que de los países que la integran, con la renovación de sus instituciones reflejan los cambios constitucionales entre los años 1972 y el 1999 del pasado siglo, 16 países modificaron sus constituciones políticas al incorporar las preocupaciones de la sociedad. Este resultado obtenido en la investigación por Brañes, ha permitido que figuren un número importante de disposiciones que refrendan la protección ambiental y la promoción de un modelo para lograr la meta del desarrollo sostenible (QUI-

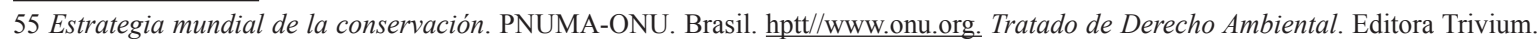
España.p. 80

56 Cumbre Mundial del Medio Ambiente. Brasil. La problemática ambiental mundial y las principales acciones a realizar por los países contaminadores. $\mathrm{hptt} / / \mathrm{www}$.onu.org

57 Declaración del Día Mundial del Medio Ambiente. Llamado a la preservación del medio ambiente, para concientizar a los pueblos y a los estadistas. $\mathrm{hptt} / /$ www.onu.org
} 
ROLA SUÁREZ, D.2013). ${ }^{58}$ Lo evidencian las constituciones de Panamá (1972), Cuba (1976), Perú (1979, sustituida en 1993), Ecuador (1979, sustituida en 1998), Chile (1980), Honduras (1982), El Salvador (1983), Guatemala (1985), Haití (1987), Nicaragua (1987), Brasil (1988), Colombia (1991), Paraguay (1992), Argentina (1994), República Dominicana (1994) y Venezuela (1999). Doce de estas constituciones fueron promulgadas entre los años 1972 y 1992, en el período de veinte años que medió entre la Conferencia de Estocolmo y la Conferencia de Río (BRAÑES BALLESTEROS, R. 1997). ${ }^{59}$

El PNUMA, en el siglo XXI ejecutó otros nuevos análisis denominado: "economía verde", para conocer como se ha mantenido, comportado y evolucionado el marco regulatorio en los 33 países que integran la América Latina y el Caribe en materia de protección al medio ambiente, dentro de las metas del desarrollo sostenible y la erradicación de la pobreza establecidas por el PNUMA-ONU, permitieron conocer de sus conclusiones, a partir de cómo se aprecia la regulación de la protección ambiental, arrojó: "casi todos los países de América Latina y el Caribe presentan una estructura legal similar: en la cabeza, cláusulas constitucionales ambientales, luego una Ley General, Ley de Bases, Marco u Orgánica del Ambiente, y leyes sectoriales ambientales" (CAFFERATTA, N. 2013). ${ }^{60}$

Rey Santos, experto en política ambiental cito: "las normas constitucionales que se ocupan del medio ambiente constituyen una parte muy relevante del derecho ambiental, porque dichas normas trazan pautas esenciales de obligada consideración por el legislador y por tanto, guían el actuar del órgano legislativo. (...) Por otra parte, su carácter de norma estable supone que la modificación o derogación de la Constitución está sometida a condiciones especiales y su condición "rígida" determina que el proceder para tales cambios esté generalmente recogido en la propia Constitución. Esta estabilidad se trasmite a los presupuestos ambientales que contiene. Todos estos elementos convierten a la normativa constitucional en un ámbito exclusivo y notable para el análisis de la evolución $y$ marcha del derecho ambiental." (SANTOS REY, O. 2013). ${ }^{61}$

Similares a estas evidencias obtenidas en los inicios de este siglo XXI, están los resultados de los estudios realizados para analizar los progresos de la institucionalidad ambiental en la región a diez años después de la Cumbre Mundial de Río de Janeiro en el año 1992, realizados también por Brañes Ballesteros, quien resaltaba: "la compleja historia politica reciente de gran mayoría de los 20 países que componen América Latina llevó a la renovación de sus instituciones, reflejados en cambios constitucionales citados" (BRAÑES BALLESTEROS, R. 2000). ${ }^{62}$

Se aprecia, la preocupación por la protección del bien jurídico ambiental y del desarrollo sostenible en la región Latinoamericana ha conllevado a insertar la temática ambiental a partir de las Leyes fundamentales. En el siglo XXI, se ratifican las evidencias que confirman lo señalado en los estudios realizados en el término de los años de 1976 hasta el 1992, después del 1992 y en el 2013 en los países de la región de Latinoamérica y el Caribe; demuestran el desarrollo de una legislación en materia ambiental, varía acorde a la tradición jurídica de cada país,

$58 \mathrm{El}$ constitucionalismo en América Latina con la práctica democrática y participación ciudadana, originado en la Constitución colombiana de 1991 y la Constitución de Ecuador de 1998, muestran avances al reconocer los derechos ciudadanos, cambia con la Constitución del 2008, el Estado Ecuatoriano con carácter constitucional de Derecho. En Venezuela en 1999, se da un proceso originario, la Constitución nace a partir de la voluntad popular. Bolivia, Constitución del 2009, encamina la creación de un Estado democrático, soberano y de participación popular. PNUMA. Sumak Kaway. Hacia un Nuevo Pacto Social en Armonía con la Naturaleza. El Buen Vivir: una vía para el desarrollo sustentable. Editora Abya-Yala.Ecuador.pp.7-79

59 Informe del Derecho Ambiental Latinoamérica. Análisis histórico-doctrinal y jurídico del Derecho Ambiental. Retos para su mejora. 60 Constitucionalismo e Institucionalidad Ambiental en Latinoamérica. La democracia participativa en las decisiones ambientales. Editora Ine-Semarnat. México. p.23

61 La participación ciudadana en los textos constitucionales, a raíz de la Democracia Participativa. En Derecho Ambiental Cubano. Editora Félix Varela. Cuba.

62 Informe sobre el desarrollo del Derecho Ambiental Latinoamericano. Su aplicación después de diez años de la Conferencia de las Naciones Unidas sobre el Medio Ambiente y el Desarrollo. PNUMA-ONU México.p.33 
en general han mantenido en común establecer las líneas generales de la política ambiental nacional, los principios de la misma y de los instrumentos y herramientas para implementarla por la Administración Pública (GUDYNAS, E. 2009). ${ }^{63}$ Afirmación que coincide con la aportada por los juristas involucrados en este análisis sobre la situación actual del Derecho Ambiental y cito:

las Constituciones, las Leyes marco o generales, conforman el núcleo duro y estable de la institucionalidad ambiental de los países de la región objeto muestral, para reconocer si estas resultan ser productivas con la aparición de la economía y contabilidad ambiental en pos del desarrollo sustentable vinculadas a la práctica de la auditoría ambiental.

\subsection{LA CONSTRUCCIÓN DE LA EM- PRESA ECOLÓGICA, VÍNCULO CON EL CONTROL AMBIENTAL A TRAVÉS DE LA AUDITORÍA PÚBLICA.}

El PNUMA, ha considerado sobre la protección ambiental, la necesidad de implementarse la economía ambiental para lograr la sostenibilidad, con una ordenada implementación dentro de estas empresas, meta no lograda en todos los países muestreados. Todo este material científico considera a la economía ambiental dentro del desarrollo sostenible y la erradicación de la pobreza, como uno de los instrumentos más importantes para lograrlo, al ofrecerles a estos empresarios nuevas alternativas. Contribuye al aumento económico con patrones de sostenibilidad al permitir mayor inclusión social, mejor bienestar humano y más oportunidades de empleo y trabajo decente para todos, mantener saludable los ecosistemas al utilizar los SGA; es a la vez un instrumento y una herramienta para la Administración Pública en la toma de decisiones, tiene carácter interdisciplinario en su concreción dirigidas al ciudadano en la protección del medio ambiente y sus recursos naturales en la construcción de la empresa ecológica (EMBID ARAUJO, A. 2006) . ${ }^{64}$

En Cuba, los estudios en materia legislativa realizados en el 2013 por el PNUMA demuestran que no ha existido una construcción jurídica adecuada de los conceptos economía y contabilidad ambiental dentro del sistema contable del país, que permitirían transitar a la aplicación de las herramientas de gestión en el sector estatal con la Auditoría Ambiental para conformar la empresa ecológica, sin menospreciar la producción de múltiples de normativas que abordan la temática ambiental por el CITMA vinculadas a la práctica de este tipo de control, aplicado a través de la inspección, y aún no reconocida dentro de los articulados de la normativa ambiental marco establecida en el país (GARRIDO VAZQUEZ, R. 2013) ${ }^{65}$

En este mismo sentido, es adecuado subrayar lo señalado por el PNUMA y cito:

(...) las políticas de economía ambiental en el contexto del desarrollo sostenible y la erradicación de la pobreza deberán ser compatibles con el derecho internacional; respetar la soberanía nacional de cada país sobre sus recursos naturales, al tener en cuenta sus circunstancias, objetivos, responsabilidades, prioridades y margen de acción con respecto a las tres dimensiones del desarrollo sostenible” (...).

Introducir estos instrumentos económicos ambientales en la contabilidad de las empresas,

63 El mandato Ecológico. Derechos de la Naturaleza y Políticas Ambientales en la Nueva Constitución. Editora Abya-Yala.Ecuador. pp.7-78

64 El ciudadano y la Administración". En Revista del Instituto de Administración Pública No. 10. España. p.24 Coinciden Agustín, GORDILLO. Tratado de Derecho Administrativo. T II. El Derecho a un Medio Ambiente sano. Editora Iustel. Argentina. 2006. p.15 Miguel, SANCHEZ MORON. Derecho Administrativo. El concepto de ciudadano ambiental: equilibrio natural para la tranquilidad. Le preocupa lo inesperado, la incertidumbre manifestada por la irregularidad del clima, por la inestabilidad de los fenómenos naturales y por un calentamiento que no se modifica.6ta ed. Editora Tecnos. España.2010.p.440.

65 Las Constituciones y de las Leyes Marco o Generales del Ambiente. PNUMA-ONU. Argentina. hptt//www.planetaverde.org.ar Desde posiciones contables y jurídicas, constatan la interdisciplinariedad de ambas ciencias, con la aplicación de los instrumentos de gestión ambiental (Auditoría), de otras formas de gestión, puede consultarse la obra de. Estudio de caso: Cuba. Aplicación de instrumentos económicos en la política y la gestión ambiental. Cuba. pp.33-40. 
buscan la mejoría del bienestar humano y la equidad social, el respeto a la naturaleza y los recursos que proporciona, de los ecosistemas y reconocer la diversidad cultural donde la práctica de la Auditoría tiene influencia en modificar patrones de conductas contrarios al desarrollo sostenible (GARCÍA SALAZAR, E. 2008). ${ }^{66}$

Permitirán todos estos resultados con la práctica de esta actividad de control, desarrollar políticas para promover el uso de los recursos naturales de forma eficaz con bajas emisiones de carbono, eficiencia energética, sustituir los combustibles fósiles por energías renovables menos contaminadoras al modificar la matriz energética, proteger la biodiversidad, los recursos genéticos y los servicios ambientales de los ecosistemas, la promoción de inversiones e innovaciones de corte ambiental, las inversiones en desarrollo de capacidades y fortalecer la gobernanza e institucionalidad ambiental. Su implementación, ejecución, control y observación respecto a la normativa jurídica en materia administrativa-ambiental serán competencias de la Administración Pública hacia el ciudadano (PNUMA-ONU. 2010). ${ }^{67}$

Los conceptos de economía y contabilidad ambiental (TUAPEREDA, J.2010) ${ }^{68}$, por la transversalidad de la cuestión ambientalista y la influencia dentro de los ordenamientos jurídicos analizados de Latinoamérica, el Caribe, Norteamérica y la Unión Europea, confirman lo señalado, demuestran los resultados de los estudios realizados en base a valoraciones de las fuentes de valor histórico-jurídico, idioma común, rasgos culturales, sociales, regulaciones jurídicas y administrativas en matera ambiental a partir del texto constitucional y del derecho sustantivo desarrollado por cada país vinculados al control ambiental.

A partir de todo este estudio realizado a los ordenamientos jurídicos de estos países muestreados por este autor, se evidencia: dentro del nuevo constitucionalismo figuran un número importante de disposiciones referidas a la preocupación por la protección medio ambiental y a la promoción del desarrollo, al insertárseles cuestiones ambientales que parten de las Leyes fundamentales desde el pasado siglo hasta la actualidad con una dimensión interdisciplinaria; permiten confirmar que existe una democracia participativa por parte del ciudadano en la protección del medio ambiente. Refrendado por los resultados del estudio desarrollado en la región desde las ciencias jurídicas por investigadores del derecho en este siglo como Caferrata (CAFERRATA,N.2013) ${ }^{69}$ y Rinaldi (RINALDI,G.2013) ${ }^{70}$, en relación a la técnica de introducir las políticas ambientales a partir del texto constitucional, la responsabilidad ambiental, la implementación de los SGA, la auditoría ambiental, la introducción de la economía y contabilidad ambiental, la póliza ambiental, la reducción de los costes en las empresas, la reducción de la contaminación, el uso de tecnologías limpias y de otras herramientas de gestión, para conformar la empresa ecológica y de esta manera acercarse a la meta del desarrollo sostenible (VIGURI PEREA, A.2010) ${ }^{71}$.

La protección ambiental, los métodos de control aplicados, la relación del Derecho Ambien-

66 Economía ecológica frente a economía industrial. La necesidad de implementar la contabilidad ambiental en las empresas. En Revista Argumentos No.56. México. pp.68-79.

67 Informe Desarrollo Humano. La verdadera riqueza de una nación está en su gente. IDH es una medida del desarrollo humano. Mide el progreso medio de un país en tres dimensiones del desarrollo humano: disfrutar de una vida larga y saludable, acceso a educación y nivel de vida digno. Media geométrica de índices normalizados que miden los logros en cada dimensión.hptt//www.idh.org pp.2-79

68 Evolución y situación actual del pensamiento contable. La partida doble, visión económica y científica de la contabilidad con la protección ambiental, vínculo con el Derecho. España.pp.27-119.

69 Naturaleza jurídica del Derecho Ambiental. Orígenes del Derecho al Medio Ambiente. PNUMA-ONU. Argentina. hptt//www. planetaverde.org. p.3

70 La Evaluación del Impacto Ambiental Estratégica. Nexo de la evaluación ambiental con la auditoría ambiental. PNUMA. Argentina. hptt//www.planetaverde.org.pp.7-37

71 La responsabilidad en materia medioambiental: el seguro ambiental. La póliza ambiental vinculada a la auditoría ambiental. En Revista Española de Seguros No. 5. España.p.74. 
tal con otras ramas del derecho y el vínculo con otros saberes. Permiten señalar, la necesidad de actualizar la legislación cubana a partir de la norma constitucional, la ley marco ambiental y el derecho sustantivo vinculado a la política ambiental en relación con las instituciones estudiadas (ALARCON GARCIA, G.2012) ${ }^{72}$

Los ordenamientos jurídicos de la región Latinoamericana y Caribeña con el de la Unión Europea, comprobamos que se distinguen con la aprobación de una nueva Ley de Responsabilidad, originada por los graves episodios de contaminación que ocurren en este continente, exigen nuevos sistemas de responsabilidad a la Administración Pública. Normativa está elaborada a través de un proceso de participación pública, para conformar un sistema de Responsabilidad Objetiva, centrada en la recuperación de lo degradado, basada en los principios de prevención $y$ en el de quien contamina paga. Se ratifica además, la pertinencia de la protección ambiental a partir del texto constitucional y su implementación en el desarrollo del derecho sustantivo ambiental. Se distinguen dentro de esta normativa ambiental de la región de Latinoamérica y el Caribe en este tipo de responsabilidad.

En el continente de América del Norte, es tomado como país en atención al criterio de orígenes de la institución estudiada, para conocer la regulación jurídica en materia ambiental a los Estados Unidos de América: la NEPA ha dado una respuesta legislativa de un efecto ambientalista ecológico, conformado en la sociedad norteamericana, el Gobierno y el Poder legislativo no la ha obviado. Ley que no es substantiva en el entendido de que no imponen a las instancias gubernamentales la consecución de determinados resultados de una materia incompleta, es procedimental y procedimentalista. Se detalla solo en el proceso de la toma de decisiones y las formas de actuación que el Gobierno y las Agencias Federales, deberán tenerse en cuenta en sus resoluciones cuando las mismas puedan tener ciertas repercusiones sobre el medio ambiente. Los aspectos de interés se encuentran en la sección 2 de la Ley, con una carga valorativa. La Constitución Federal, no recoge una mención explícita al derecho de los ciudadanos a gozar de un medio ambiente adecuado o sustentable. Existen intentos doctrinales y jurisprudenciales para reconocer este derecho en el seno de la propia Constitución Federal, tomando como punto de partida una interpretación del resto de las disposiciones del texto constitucional, fundamentada en la IX Enmienda. Dado por las regulaciones ambientales al impactar el comercio entre los Estados de la Unión y los foráneos (PNUMA-ONU.2005) $)^{73}$

Otros trabajos científicos valorados desde la ciencia del Derecho, abordan como ha estado tratada dentro de los ordenamientos jurídicos de Latinoamérica y el Caribe esta tipología de auditoría, al ser reconocida como un instrumento o la herramienta de gestión ambiental (CARMONA LARA, M.2010) ${ }^{74}$, coinciden en señalarla, entre los modos de actuación de la Administración Pública, es considerada como prestación de servicio público, actividad de control y de fomento, se aprecia estar vinculada con la inspección ambiental y la potestad sancionadora que asume la Administración Pública de sus funcionarios ante sus faltas por cometer daños a los recursos naturales, es solicitada por estos empresarios para obtener una certificación ambiental de industria limpia y poder acceder a mercados. Concuerdan que su regulación legal parte desde el texto Constitucional, Leyes generales del medio ambiente, de gestión ambiental, de la Contraloría y especiales para la Auditoría Ambiental, para lograr un desarrollo adecuado, se confirma como institución jurídica a partir

\footnotetext{
72 ¿Son los tributos ambientales una opción para la financiación de las HHPP? Reflexiones sobre la fiscalidad ambiental autonómica. La fiscalidad ambiental establece los tributos sobre tres bienes naturales: las aguas litorales, los residuos y la atmósfera. En Revista Cuaderno Interdisciplinar de Desarrollo Sostenible. No. 9. España. pp.205-277

73 Auditoría ambiental: evolución histórica y su entorno político institucional. Comité internacional de prácticas de Auditoría. hptt//www. iac.org.pp.5-28

74 Análisis desde posiciones jurídicas, permiten conocer el método aplicado a esta institución de la Auditoría para realizar el control ambiental a partir de su tutela en los ordenamientos jurídicos, desde el Derecho Administrativo hasta el Derecho Administrativo Ambiental. México. p.12
} 
de ser reconocida en la doctrina y normativa ius administrativa y la ambientalista; se aprecia además su vínculo en su práctica con Leyes de Salud y de Urbanismo, se reconoce el trabajo de las ONGs ambientalistas, la protección de los recursos minerales como: el agua, los agro tóxicos, la gestión forestal pública, el patrimonio genético, los tipos de responsabilidad ambiental, la tributación ambiental, la solución de los conflictos en las Fiscalías Ambientales y su conclusión en sede judicial ambiental. Demuestran la coyuntura de la democracia participativa a partir del nuevo constitucionalismo en Latinoamérica, se destacan las Constituciones de Ecuador, Venezuela y Bolivia como las que han tratado la cuestión ambientalista con mayor rigor dentro de sus articulados.

En la Unión Europea se evidencian los resultados analizados de la producción científica de juristas en relación a los resultados académicos y prácticos sobre la Auditoría (FERNANDEZ DE GATTA SANCHEZ, D.2009) $)^{75}$, coinciden al señalar que la protección del bien jurídico ambiental se materializa a partir del texto Constitucional, las Leyes generales del Ambiente, en Códigos Ambientales; en su conjunto conforman un núcleo estable a nivel normativo, brindan solidez y sustento para el posterior desarrollo de políticas ambientales públicas al incorporarse los principios de economía y contabilidad ambiental (BARRATERO MARIA, A.2008).$^{76}$ Prosiguen en sus criterios al confirmar el uso de la auditoría ambiental, con el uso complementario de las normas ISO, las normas EMAS y las Directrices de las EFS; permiten detectar deficiencias, irregularidades en acatar la legislación ambiental de acuerdo a un proceso productivo o productos para propiciar opciones de mejora y uso racional de los recursos naturales, disminuir la huella ambiental generada vinculada a la contaminación, la exigencia de la responsabilidad ambiental objetiva ante la comisión de daños, la aplicación de incentivos fiscales (TERAN CONTRERAS,J.2011) ${ }^{77}$, el tributo ambiental vinculado al vertido, los servicios ambientales, la cobertura económica a través del seguro ambiental y la responsabilidad social empresarial al obtenerse la certificación ambiental (LASAGABASTER HERRARTE, I.2009).$^{78}$ Señalan su vínculo con el desarrollo socio-económico al conformarse los tres pilares fundamentales del desarrollo sostenible (RUIZ GARIJO, M.2011). ${ }^{79}$

En síntesis, esta tipología de auditoría, luego de los análisis realizados desde los saberes académicos y prácticos, por su impacto socio-económico a partir de los resultados de su aplicación como herramienta de gestión, preservará y mitigará los problemas ambientales al conocerse los índices de contaminación, permitirá trazar estrategias por parte de los empresarios como las técnicas de construcción "verdes" in situ que hoy se socializan en el mundo; realizada por las Contralorías al permitir evaluar los resultados obtenidos por las empresas estatales en la adecuada, eficiente, económica, eficaz y equitativa administración del patrimonio público de los recursos naturales y del medio ambiente, en su llamado por la Ley de vigilar y realizar el control fiscal ambiental.

Dentro de esta economía globalizada, asociada a modelos de desarrollo basados en las leyes del capital y valores éticos que justifican el deterioro de los ecosistemas y la pérdida de la biodiversidad, al existir una injusta distribución de las riquezas, que propician el aumento de la pobreza, vinculados a los procesos de homoge-

75 El criterio desde posiciones jurídicas en la Unión Europea en torno al control ambiental, con la aplicación de las herramientas de gestión (Auditoría). Derecho Ambiental, aspectos generales sobre la protección jurídica del medio ambiente. España.p.4 Coincide Ramón, MARTIN MATEO Manual de Derecho Ambiental. España. pp.11-119.

76 La metodología ABC en la acumulación y distribución de los costos medioambientales. En Revista de la Universidad de Los Andes No. 4. Colombia. pp.37-67.

77 Instrumentos fiscales de la gestión ambiental. Políticas de control de contaminación, la reducción de índices contaminadores, los estándares ambientales y la aplicación de sanciones. En Revista de Economía Aplicada No. 29. España. pp.1-12

78 Medio Ambiente y obligación de difusión por la Administración Pública. Editora Lette. España. pp.59-88 INTOSAI. EFS. Auditoría Ambiental y auditoría de regularidad. .

79 Más de diez años de Responsabilidad Social Empresarial. ¿Para cuándo su regulación jurídica y el establecimiento de incentivos fiscales? En Revista Economía Nº7. España. 
LA AUDITORÍA AMBIENTAL COMO FUNCIÓN DE LA ADMINISTRACIÓN PÚBLICA EN LA PROTECCIÓN DEL BIEN PÚBLICO AMBIENTAL, PARA CONSTRUIR LA EMPRESA ECOLÓGICA COMO META DEL DESARROLLO

neización cultural, orientados a exportar patrones insostenibles de consumo que caracterizan a estas sociedades económicas desarrolladas; elementos sustantivos de la problemática ambiental al incidir de manera desequilibrada y desfavorable entre el Norte y el Sur. Por lo que esta herramienta estudiada, entrará a jugar un rol para lograr el equilibrio entre los avances tecnológicos y la naturaleza para la construcción de la ecoempresa.

\section{CONCLUSIONES}

- La multidimensionalidad de esta tipología de auditoría, analizada a partir de sus características identitarias, es reconocida por la doctrina como el proceso que examina de manera exhaustiva los equipos y tecnologías en una empresa, evalúa los índices de contaminación, los riesgos generados, informa a los empleados sobre la problemática ambiental para que apliquen buenas prácticas ambientales, evalúa la política y la normativa ambiental para determinar medidas correctivas y preventivas que se precisen al practicarse esta actividad de control ambiental, se ejecuta de forma voluntaria u obligatoria por las Contralorías o Sociedades Civiles de Auditoría acreditadas en correspondencia del país; en materia legal su regulación se declara en los ordenamientos jurídicos desde el texto constitucional, como desarrollador de la normativa sustantiva ambiental y en leyes especiales, de manera supletoria son utilizadas las normas ISO 14000, 19011 y las EMAS, como otras normas jurídicas vinculadas a la salud y a la protección del medio ambiente laboral, su naturaleza jurídica es proteger el bien jurídico ambiental como bien público, se vincula como actividad de control con otras herramientas de gestión como son la Evaluación de Impacto Ambiental, la Licencia Ambiental y con la aplicación de instrumentos contables e incentivos fiscales para su desarrollo.

- Los elementos objetivos, aparecen definidos a partir de su práctica, en un programa como proceso sistémico, a través de un procedimiento a realizarse por los equipos de auditores, integrado por profesionales de diversos saberes, de ahí que se reconozca su interdisciplinariedad, transdisciplinariedad y multidisciplinariedad, se ve mate- rializada a través de un contrato de servicios; los empresarios la solicitan para conocer los índices de contaminación generados por su empresa y en que niveles permisibles están, su resultado final se concretará con la entrega de la certificación ambiental, se aplicará dentro del respeto a los indicadores de la responsabilidad social empresarial. Sus resultados serán comunicados en el informe final de la auditoría por el equipo auditor, están implicados los auditados en relación con las deficiencias detectadas en el control ambiental como sujeto pasivo, siendo exigible la responsabilidad ambiental en sus aristas.

- Los elementos subjetivos para su práctica, se reconocen a partir de su ejecución en la empresa estatal, no estatal u otras formas de gestión; al aplicarse las normativas ambientales y de auditoría, las normas y principios contables, las normas ISO y las EMAS, en su conjunto permiten armonizar progreso y naturaleza a través de la aplicación del fomento ambiental como una de estas políticas públicas para lograr la sostenibilidad, meta del PNUMA dirigida a estos gobiernos. Todos estos postulados inciden en el cambio propuesto para modificar los patrones de la cultura organizacional y en la conducta del empresariado en la organización auditada, en relación con los modos de actuación en materia de protección ambiental para formar una conciencia ambiental adecuada. Permitirán a las empresas sean reconocidas como industrias limpias, con los beneficios incorporados a través de una imagen positiva en relación a las ventas y obtención de ganancias en el mercado de su producción o servicios que comercialicen ante las barreras comerciales establecidas y tener acceso a coberturas a través de pólizas ambientales ante sucesos eventuales o fortuitos vinculados al medio ambiente.

- Esta tipología de auditoría, aparece regulada dentro de los ordenamientos jurídicos como una actividad de control o de servicio público dirigida a las formas de gestión estatal o no estatal; es ejecutada a través de normativas jurídicas ambientales y procedimientos administrativos establecidos por las Entidades Fiscalizadoras Superiores para su concreción como elementos formales, al permitir corroborar las evidencias del control practicado. 
- En el orden teórico, los criterios académicos sobre esta tipología de auditoría, se reconoce concebida dentro de las herramientas de gestión ambiental, a partir de la sistematización de su concepto como institución jurídica para proteger al bien jurídico ambiental, desde la doctrina ius administrativa hasta la ius ambientalista, como contribución a los presupuestos teóricos concebidos a partir de su íter histórico, orígenes, principios, evolución, tratamiento doctrinal y legislativo dentro de los ordenamientos jurídicos, la complejidad de los fenómenos asociados a diversas circunstancias para su ejecución, matices socioculturales y económicos, con el fin de su mejora y aplicabilidad en el sector estatal. De su desempeño adecuado dependerá que se logre producir sin afectar el medio ambiente, con la buena marcha de los procesos de planificación, organización, ejecución, control y evaluación de la gestión ambiental, dependerá que se cuente con un ambiente sano (calidad de vida) y ecológico equilibrado, asociado a programas de gestión de residuos, evaluación de las cargas ambientales; tal y como se reconoce a partir del texto constitucional para el desarrollo sostenible a través de las empresas ecológicas.
- El vínculo con otras normativas jurídicas, para conocer los niveles de eficiencia y eficacia, adecuadas con la realidad a la que pretenden dirigirse, en la construcción apropiada de las normativas y de los órganos, organismos e instancias encargados de promoverlas y vigilar su respeto, a través de los mecanismos regulados en las materias de Derecho Civil, Administrativo y Penal en relación a la exigencia de la responsabilidad se reflejan en la práctica de esta actividad de control ambiental.

- La evolución de esta actividad de control ambiental, su iter desde sus orígenes hasta el siglo actual, el tránsito desde las ciencias contables hacia las jurídicas, con la adición de nuevos elementos incorporados en las etapas analizadas, la hacen más completa y moderna, en relación con los problemas ambientales actuales. Reconocida como institución jurídica desde el Derecho Administrativo como eje trasversal del Derecho Ambiental, dentro de las herramientas de gestión ambiental con la inserción de otras herramientas e instrumentos que conformarán en su práctica la industria ecológica y transitar hacia la meta del desarrollo sostenible.

\section{REFERENCIAS}

AFONSO DA SILVA, J. (2009) Direito Ambiental Constitucional. Editora Método. Brasil.

AGUILERA KLINT, F. (2010) De la economía ambiental a la economía ecológica. Editora Icaria. España.

AGUILAR TORRES, J. (2010) La responsabilidad civil objetiva por daños al medio ambiente y su regulación en México. Editora Redipal. México.

ALVES SILVA, L.F. (2014) Derecho Ambiental. Editora Lumen. Brasil.

ÁlVAREZ, A. (2010) Responsabilidad civil por daño ambiental. Instituto de Derecho comparado de la Academia de Derecho de Córdova. Argentina.

ANTUNES BARREIRA, P. (2010) Derecho Ambiental. Universidad de Goias. Brasil.

ARMISÉN CAUSARANO, J.P. (2008) Concepto, alcances y resultados actuales de la auditoría ambiental. Universidad Nacional de México. México.

ARNER GUERRE, A. (2013) Responsabilización voluntaria de la industria en la protección medio ambiental. Universidad de Zaragoza. España.

ARISTAZABAL OSSA, H. (2010) Auditorías ambientales. Contraloría General de Colombia. Colombia. 
LA AUDITORÍA AMBIENTAL COMO FUNCIÓN DE LA ADMINISTRACIÓN PÚBLICA EN LA PROTECCIÓN DEL BIEN PÚBLICO AMBIENTAL, PARA CONSTRUIR LA EMPRESA ECOLÓGICA COMO META DEL DESARROLLO

SOSTENIBLE.

ARIAS MENDOZA, J. J. (2010) Bienes y servicios ambientales. En: Revista de estudios de economía aplicada. España.

ARIÑO ORTIZ J. M. (1997) Significado actual de la noción de servicio público. El nuevo servicio público. Editora Marcial Pons. España.

BASURTO GONZÁLEZ, D. (2012) Responsabilidad Social y Ambiental en las Empresas. En: Revista Política y Gestión Empresarial. México.

BESARES ESCOBAR, M.A. (2011) Derecho Penal Ambiental. Editora Porrúa. México D. F.

BELLMONT, Y. (2012) El concepto de justicia ambiental. En elementos para una teoría de la justicia ambiental y el estado ambiental de derecho.1era ed. Universidad Nacional de Colombia.

BERNAL PEDRAZA, A.Y. (2009) Responsabilidad ambiental de las empresas, un compromiso ético con el desarrollo sostenible. Universidad Externado de Colombia.

BERNAL PISFIL, F. (2010) Auditoría Ambiental o Ecoauditoría. En: Revista Actualidad Empresarial, No 201.Colombia.

BELMONTE MARTIN, I. (2009) La Ecoauditoría: un instrumento para la defensa del medio ambiente. En: Revista de la Facultad de Ciencias Jurídicas y Sociales de Elche. España.

BERMEJO VERA. (2008) La Administración inspectora. Editora Thomson Civitas. España.

BIONDI, M. (2010) En busca de aportes teóricos para lograr la identidad de la contabilidad ambiental. En: Revista Contabilidad y Auditoría. No 32. Universidad de Buenos Aires.

BOTASSI, C. A. (1997) Derecho Administrativo Ambiental. Editora Platense S.R.L. Argentina.

BOtero VILleGAS, R. (2010) Marco Legal del Control Fiscal Ambiental. Contraloría General. Colombia.

BONILlA PRIEGO, M. (2000) Algunos problemas en la determinación del coste medio ambiental en la empresa. En: Revista de Técnica Contable. No. 615. España.

BOJÓRQUEZ-TAPIA, L. (1998) Aspectos metodológicos de la auditoría ambiental. PEMEX: ambiente y energía. Los retos del futuro. UNAM. México.

BORREEGAARD, N. (1997) Sistemas de incentivos financieros para la introducción de tecnología ambiental. Instrumentos económicos de la política ambiental. Política Tributaria e Impuestos Ecológicos. Editora Ambiente y Desarrollo. Argentina.

BOKOBO MOICHE, S. (2000) Gravámenes e incentivos fiscales ambientales. En: Revista Trivium. España.

BOWEN, H. (1953) La responsabilidad social de los empresarios. La auditoría, vínculos con otras ciencias y saberes. Estados Unidos de América.

BURDYSHAW, C. (2011) Experiencia de otros Tribunales Ambientales en el Mundo. En: Revista Justicia Ambiental. No.4.Chile.

BRAÑES BALLESTEROS. R. (2003) La Fundación del Derecho Ambiental en América Latina. Chile.

BRACAMONTES ALDANA, J. (1994) Marco legal de las auditorías ambientales en el mundo. La protección ambiental con la combinación de legislación, regulación y políticas voluntarias a la industria. UNAM. México. 
BRANDON, J. (1995) Reingeniería. Como aplicarla con éxito en los negocios. Editora Mc Grac Hill. España.

CARDONA GALLO, M. (2007) Minimización de Residuos: una política de gestión ambiental empresarial. En: Revista $\mathrm{P}+$ L. Colombia.

CARMONA LARA, M. (2005) Aspectos jurídicos de la auditoría ambiental en México. UNAM. México.

CAFFERATA, N. A. (2008) Naturaleza jurídica del Derecho Ambiental. Editora INE- Semarnat. México.

CAFFERATA, N. A. (2004) Teoría de los principios del Derecho Ambiental. Editora INE- Semarnat. México.

CANOSA USERA, R. (2011) Protección constitucional de los derechos subjetivos ambientales. Editora Montecorvo. España.

CÁNOVAS GONZÁLEZ, D. (2011) Estudios sobre Derecho del Ambiente. Editora Hnos. Vadell. Venezuela.

CÁNOVAS GONZÁLEZ, D. (2012) Necesidades y potencialidades del Derecho Ambiental cubano. CITMA. Cuba.

CÁNOVAS GONZÁLEZ, D. (2013) Nuevas normas sobre responsabilidad civil por daños derivados del manejo de productos y desechos químicos. CITMA. Cuba.

CAStAÑEDA LOZANO, Y. (2010) El Ciudadano Ambiental. En: Revista Universidad de La Salle. Colombia.

CALDERÓN BERTHENEUf, J. (2011) La Auditoría Ambiental en México. Editora PROFEPA. México.

CONESA FERNÁNDEZ, V. (1997) Auditorías Medioambientales: guía metodológica. España. Editora Mundi-Prensa. España.

CONESA FERNÁNDEZ, V. (2003) Instrumentos de la gestión ambiental en la empresa. 1era ed. Editora Mundi - Prensa. España.

DA CONCEIÇÃO DA COSTA MARQUES, M. (2012) La problemática de la Auditoría Ambiental. Universidad de Coímbra. Portugal.

DE BESA ANTUNES, P. (2010) Direito Ambiental. Ed. 14. Editora Lumen Juris. Brasil.

DIEZ SANCHEZ, J. (2009) Función Inspectora. Editora Iustel. España.

DOPAZO FRAGUÍO, P. (2001) El Régimen Jurídico de las marcas de calidad ambiental. Etiqueta ecológica y tutela ambiental. Editora Exlibris. $1^{\mathrm{a}}$ Ed. España.

DUGUIT, L. (1925) Las transformaciones del Derecho Público. Editora Colin. París.

DROMI, J.R. (1998) Tratado de Derecho Administrativo. 7ma ed. Editora Ciudad Argentina. Argentina.

EGUSQUIZA PEREDA, C. (2006) Auditoría ambiental. UNAM. México.

ESCALERA IZQUIERDO, G. (1999) Implantación de la reingeniería por procesos. Actividades, técnicas y herramientas. En: Revista del Empresario. España.

FERNÁNDEZ DE GATTA, D. (2006) Derecho Ambiental. Aspectos generales sobre la protección jurídica del medio ambiente. Universidad de Salamanca. España. 
LA AUDITORÍA AMBIENTAL COMO FUNCIÓN DE LA ADMINISTRACIÓN PÚBLICA EN LA PROTECCIÓN DEL BIEN PÚBLICO AMBIENTAL, PARA CONSTRUIR LA EMPRESA ECOLÓGICA COMO META DEL DESARROLLO

SOSTENIBLE.

FERNÁNDEZ DE GATTA, D. (2004) La responsabilidad social corporativa en materia ambiental. Boletín económico ICE. España.

FERNÁNDEZ RAMOS, S. (2000) La inspección en el marco del control de la aplicación del Derecho Ambiental. En: Revista Derecho Ambiental No 24. España.

FERNÁNDEZ RAMOS, S. (2010) Inspección administrativa y la potestad sancionadora. En Blanca Lozano Cutanda. Diccionario de las sanciones administrativas. Editora Iustel. España.

FERNÁNDEZ RAMOS, S. (2009) La inspección ambiental estatal. Editora Comares. España.

FRONTI DE GARCÍA, L. (2003) La auditoría ambiental, un nuevo enfoque profesional. En: Revista contabilidad y auditoría. No 18. Argentina.

FRONTI DE GARCÍA, L. (2007) Contabilidad Ambiental, segmento contable para el Siglo XXI. Ediciones Cooperativas. Argentina.

GARCÍA ENTERRÍA, E. (2005) Derecho Administrativo. Editora Félix Varela. Cuba.

GÓMEZ GARCÍA, L.E. (2011) La Auditoría Ambiental ¿voluntaria u obligatoria? En: Revista Derecho Ambiental y Ecología. México.

GOMEZ LOPEZ, R. (2009) Generalidades de la Auditoría. En: Revista Universidad de Málaga. España.

GONZÁLEZ MALAXECHEVARRÍA, Á. (1997) La Auditoría Medioambiental, su evolución histórica y entorno politicoinstitucional. España.

GORDILlO, A. (2006) Tratado de Derecho Administrativo. 8va ed. Editora Macchi. Argentina. GRAY R. (1999) Contabilidad y Auditoría Ambiental. Editora ECOE. España. 1999.

GRANERO CASTRO, J. (2007) Como implantar un sistema de gestión ambiental según la norma ISO. Editora Pirámide. España.

JAQUENOD DE ZSOGON, S. (2004) Derecho Ambiental. Editora Dykinson. España.

JORDANO FRAGA, J. (2010) Viejos y Nuevos retos de la Evaluación de Impacto Ambiental. En: Revista Derecho y Medio Ambiente. España.

JUSTE RUIZ, J. (2007) La evolución del Derecho Internacional del medio ambiente. Universidad de Valencia. España.

JUSTE RUIZ, J. (2012) Hacia un convenio mundial sobre las evaluaciones ambientales. En: Revista Aranzadi. no. 23. España.

JUSTE RUIZ, J. (2010) Derecho Ambiental de la Unión Europea. Universidad de Valencia. España.

LÓPEZ SELA, P. (2006) Derecho Ambiental. Editora Iure. México.

LORENA BARILÁ, G. (2002) Auditoría Ambiental: El camino hacia el logro de una ventaja competitiva. Universidad de Ciencias Económicas. Argentina.

LORENZO, T. (2009) Auditoría Ambiental voluntaria. Marco jurídico ambiental de la empresa. En: Revista Novedades y perspectivas. México. 
LORENZETTI, R. L. (2008) Teoría del Derecho Ambiental. 1era ed. Editora Porrúa. México.

LOZANO CUTANDA, B. (2004) Derecho Ambiental Administrativo. 5ta ed. Editora Dykinson. España.

MARTÍN MATEO, R. (1991) Tratado de Derecho Ambiental. Vol. I. 1ra ed. Editora Trivium S.A. España.

MARTÍN MATEO, R. (1994) El etiquetado ecológico, nuevo instrumento para la tutela ambiental. Editora Trivium. España.

MARTÍN MATEO, R. (1997) Derecho Administrativo Ambiental. 6ta ed. Editora Trivium. España.

MORA RUIZ, M. (2012) Tendencias del Derecho Administrativo. El Derecho Administrativo Ambiental: Transformaciones en el Derecho Administrativo general. En: Revista Derecho y Conocimiento. España.

MURAD ROBLES, P. (2009) La Auditoría Ambiental voluntaria. Editora Semarnat. México.

MIRANDA HERNÁNDEZ, G.I. (2012) La potestad inspectora de las Administraciones Públicas. En: Revista Cuadernos de Inspección del Territorio. España.

NOGUEIRA LÓPEZ, E. (2000) Ecoauditorías, intervención pública ambiental y autocontrol empresarial. En: Revista Indret. España.

PÁEZ SANDUBETE, J. (2008) La Auditoría Medio Ambiental en la Unión Europea, una perspectiva contable. Editora Trivium. España.

PÉREZ MORENO, A. (2011) Instrumentos de la tutela ambiental. Universidad de Sevilla. España.

REY SANTOS, O. Fundamentos del Derecho Ambiental. Editora Ciabo. Cuba. 2013.

REBOLLO PUIG, M. (2009) La actividad Inspectora. Editora Comares. España.

RIVERA, L.M. (2010) Marketing de los productos ecológicos. En: Revista de la Empresa. España.

SANZ RUBIALES, I. (2010) Derecho Administrativo Sancionador. Editora Lex Nova. España.

SANCHEZ MORON, M. (2010) Derecho Administrativo.6ta ed. Editora Tecnos. España.

SALES DE FREITAS, J. C. (2013) Auditoría Externa Ambiental como instrumento de defensa del medio ambiente. En: Revista De Jure. No. 20. Brasil.

SALES, R. (1999) Auditoría Ambiental, aspectos jurídicos. Editora Malheiros. Brasil.

SOTO HUANCA, R. (2010) La Auditoría Ambiental y su proceso en el contexto de la auditoría integral. En: Revista Ciencia y Desarrollo. España.

SERRANO GÓMEZ, C. (1995) El Etiquetado Ecológico. Ministerio de Obras Públicas, Transporte y Medio Ambiente. España.

VITA ROSO, J. (2011) La auditoría jurídica perfecciona la gobernabilidad de las empresas. Editora Método. Brasil. 
